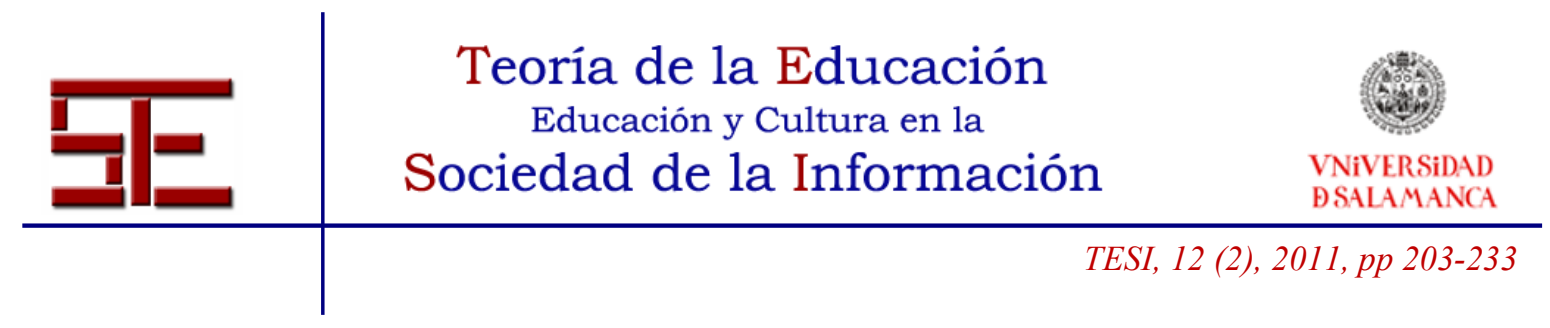

\title{
ESTRATEGIAS DE APRENDIZAJE EN ESTUDIANTES UNIVERSITARIOS. DIFERENCIAS POR GÉNERO, CURSO Y TIPO DE TITULACIÓN
}

Resumen: La investigación sobre el efecto del género, el curso o la titulación sobre las estrategias de aprendizaje no es concluyente. Resulta necesario profundizar en la forma en que estas variables están relacionadas, especialmente con análisis de corte multivariado. Se realiza una investigación de corte no experimental en la que participan 805 estudiantes universitarios. Se recoge la información con el Cuestionario de Estrategias de Trabajo Autónomo (CETA). Los resultados indican que las tres variables analizadas tienen efecto individual sobre las estrategias de aprendizaje, aunque el curso resulta el peor predictor. Del análisis de resultados se desprende la necesidad de considerar los efectos combinados que matizan, y en ocasiones contradicen, los efectos simples de las variables. El conocimiento de las estrategias por estos grupos de interés permitirá a los docentes ajustar la formación de manera específica a las diferentes formas de aprender de sus alumnos.

Palabras clave: Estrategias de aprendizaje; estudiantes universitarios; diferencias individuales; género; análisis multivariado.

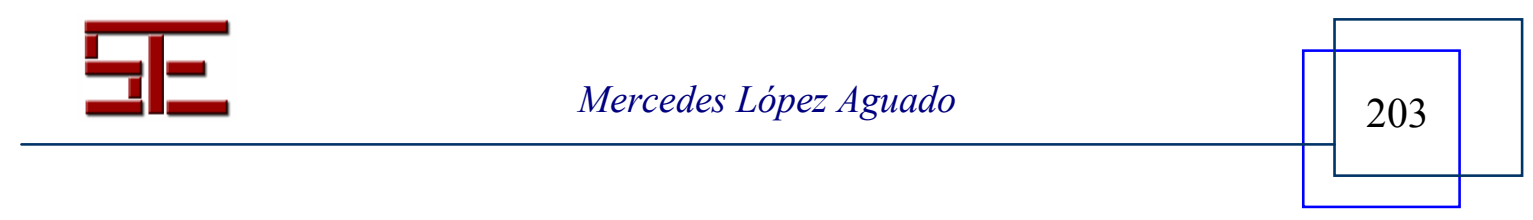




\title{
LEARNING STRATEGIES IN UNIVERSITY STUDENTS. GENDER, COURSE AND DISCIPLINE DIFFERENCES
}

\begin{abstract}
Research on gender, course or discipline effect of learning strategies is inconclusive. It is necessary to delve into the form in these variables are related, especially with multivariate analysis. There is realized a non-experimental research involving 805 college students. We collect the information with the Cuestionario de Estrategias de Trabajo Autónomo (CETA). Results indicate that the three variables have an effect on individual learning strategies, although the course turns out to be the worst predictor. Analysis results show the need to consider the combined effects that sometimes are contradictory with the simple effects of the variables. Knowledge of the strategies of interest groups will allow teachers to adjust training specifically to the different learning ways of their students.
\end{abstract}

Keywords: Learning strategies; university students; individual differences; gender; multivariate analysis.

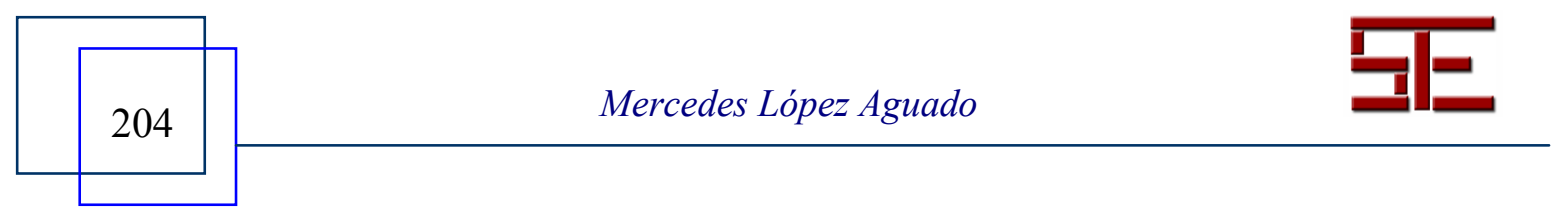




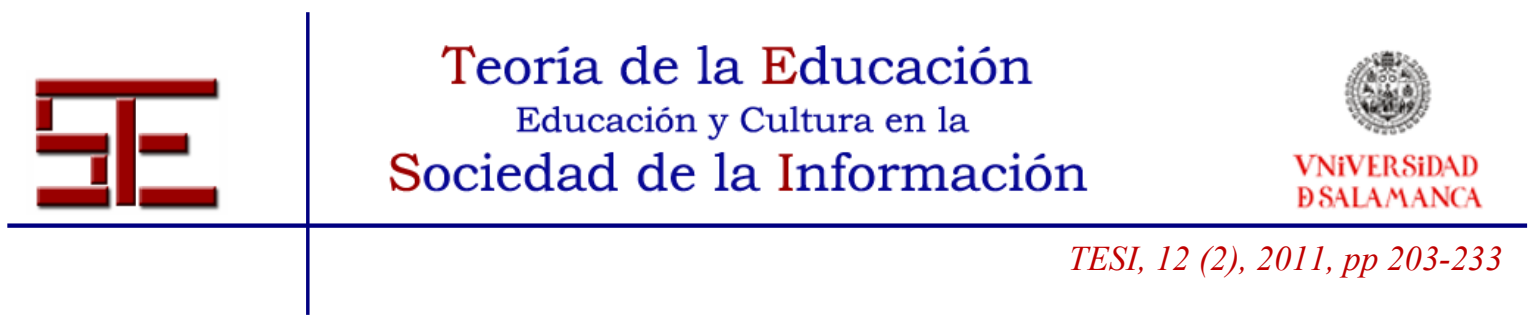

\section{ESTRATEGIAS DE APRENDIZAJE EN ESTUDIANTES UNIVERSITARIOS. DIFERENCIAS POR GÉNERO, CURSO Y TIPO DE TITULACIÓN}

Fecha de recepción: 21/05/2011; fecha de aceptación: 30/06/2011; fecha de publicación: 27/07/2011

Mercedes López Aguado

mmlopa@,unileo.es

Universidad de León

\section{1.- INTRODUCCIÓN}

La importancia de las estrategias de aprendizaje en cualquier proceso de aprendizaje está fuera de toda duda. En los niveles superiores, universitarios, especialmente en el momento actual de cambio y reforma, que pone el acento en la autonomía y responsabilidad del estudiante en la construcción de su propio conocimiento, se incrementa, si cabe, la importancia de que los estudiantes dispongan de un repertorio amplio, flexible y eficaz de estrategias que les permita enfrentar con éxito las diferentes tareas de aprendizaje que les llevarán a la adquisición de las competencias y habilidades necesarias para el futuro correcto desempeño de su labor profesional.

A pesar de lo dicho, no se pone en duda el importante papel del docente en la motivación, orientación, facilitación y guía del aprendizaje (Carbonero; Román; MartínAntón y Reoyo, 2009; Mas y Medinas, 2007) ni la forma en que las técnicas de enseñanza y evaluación empleadas por los profesores influyen en la adquisición, desarrollo y mantenimiento de las distintas estrategias de aprendizaje (García; De la Fuente y Justicia, 2002).

Sin embargo, la reforma actual de los estudios universitarios, incrementa, si cabe, la importancia de las estrategias de aprendizaje poniendo el acento en la autonomía del estudiante en la construcción de su propio conocimiento (entendido éste en sentido amplio). Esto implica que los estudiantes tendrán que asumir un papel activo en el control de su aprendizaje y, por lo tanto, seleccionar y planificar las estrategias más apropiadas a cada situación concreta de aprendizaje (Valle; González: Cuevas y Fernández, 1998) así como autorregularlas o, lo que es lo mismo, aplicar las estrategias más apropiadas para sostener de manera eficaz los esfuerzos personales dedicados al aprendizaje (Cabanach; Valle; Gerpe; Rodríguez; Piñeiro y Rosário, 2009).

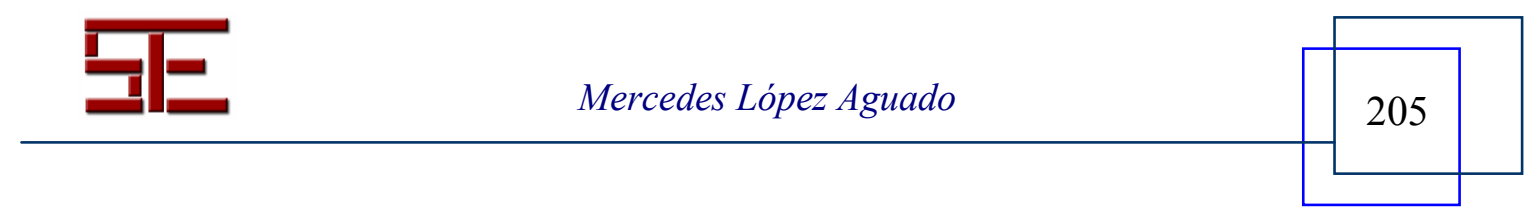




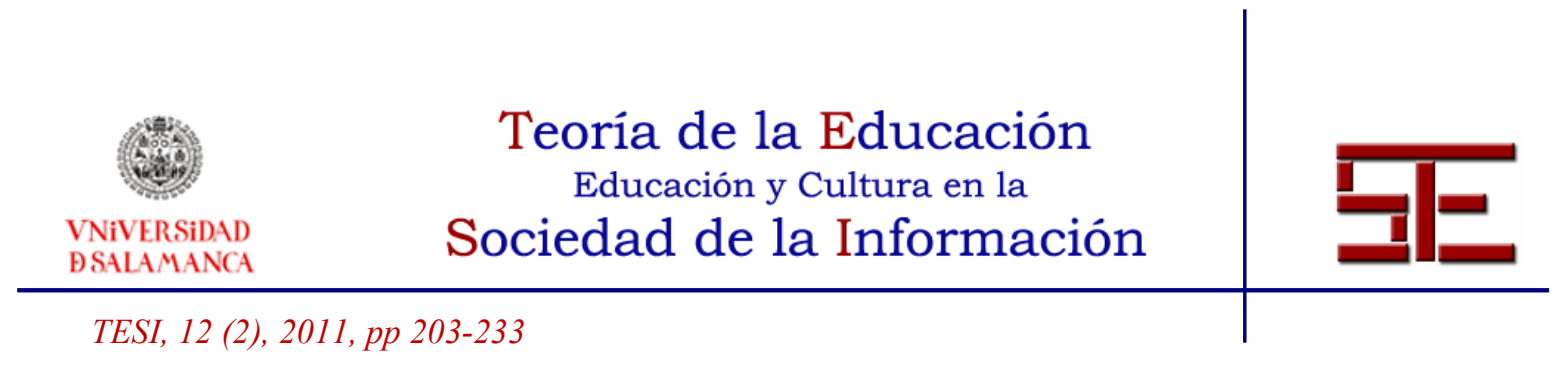

Por lo tanto, para que los estudiantes puedan hacer efectivo este liderazgo sobre su propio proceso de aprendizaje es necesario que dispongan de un repertorio adecuado, amplio y flexible de estrategias que puedan activar en función de las demandas de las distintas tareas, ya que aunque algunos alumnos pueden adquirir conocimientos sin poseer un buen repertorio estratégico, el uso de las estrategias apropiadas favorece la adquisición de aprendizajes de mayor calidad y más profundos (Núñez y otros, 1998).

Algunas investigaciones encuentran que los estudiantes universitarios disponen de un repertorio adecuado y variado de estrategias de aprendizaje y no parecen emplear estrategias superficiales o de memorización lineal o pasiva, como la realizada por Gil, Bernaras, Elizalde y Arrieta (2009) en cuatro titulaciones de Gipuzkoa.

Sin embargo, son más numerosos los estudios que encuentran que los estudiantes universitarios utilizan un pequeño conjunto de estrategias (De la Fuente y Justicia, 2003; García, Hernández y Luján, 1998), del que hacen un uso escaso (Rinaudo; Chiecher y Donolo, 2003), con predominancia de estrategias cognitivas poco complejas, concepciones de aprendizaje poco profundas (Fonseca y Rolo, 2005; Rachal; Daigle y Rachal, 2007) y escaso impacto de las estrategias relacionadas con el pensamiento crítico (Monereo, 2005).

O los que indican que, aunque parece que los estudiantes están abandonando la memorización por tácticas en las que se ven más involucrados el pensamiento y la creatividad, aún hay que seguir ahondando en la práctica de estrategias diversas que aseguren un aprendizaje más efectivo (Correa; Castro y Lira, 2004).

Como se ve, la investigación presenta resultados muy diversos. En lo que sí parece haber acuerdo es en que estas estrategias no se desarrollan espontáneamente (Vélez, 1999) y por lo tanto resulta necesario entrenarlas de forma específica.

Así, por ejemplo, Rosário (2004) considera la enseñanza de las estrategias una de las claves principales para el aprendizaje autónomo en el nuevo contexto universitario y, en la misma línea, Hernández Pina, Rosário, Cuesta, Martínez y Ruiz (2006) señalan como uno de los objetivos prioritarios del sistema universitario la equipación a los alumnos de nuevas estrategias que les permitan afrontar con éxito la construcción autónoma de su propio conocimiento.

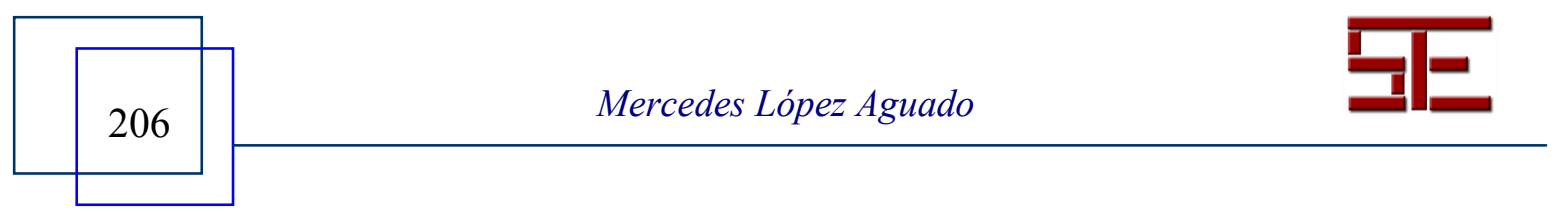




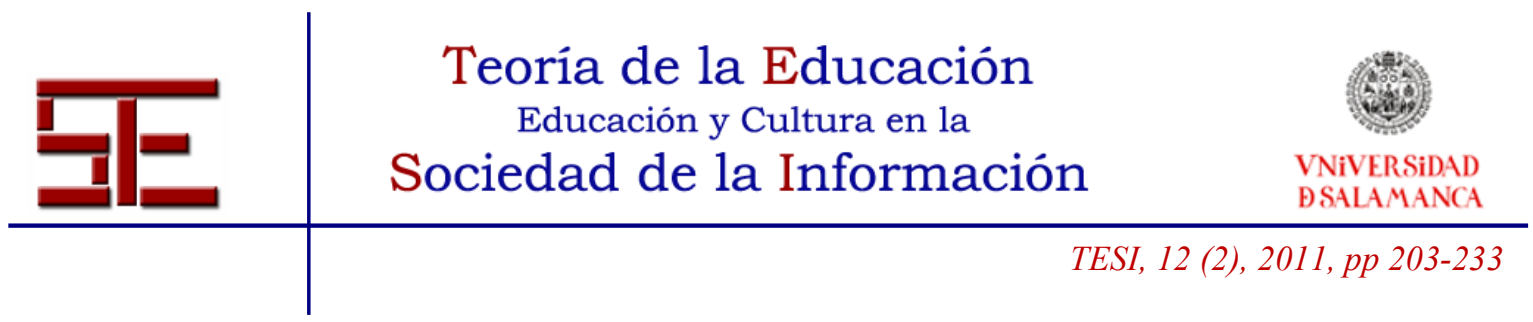

Parece, pues, imprescindible que las instituciones intervengan de manera activa con actuaciones concretas en esta línea. No obstante, antes de proponer o realizar ninguna actuación concreta, es necesario conocer con exactitud cuáles son las estrategias que utilizan los alumnos o, dicho de otra manera, establecer un diagnóstico de cada grupo e individuo concreto para poder mejorar el proceso de aprendizaje, reajustándolo al contexto del aula universitaria (Vega y Beltrán, 2003; Zabalza, 2002).

Resulta, pues, necesario conocer si algunas variables determinan diferencias contrastadas en las estrategias de aprendizaje para poder establecer acciones efectivas específicas en función de ellas. Gil, Bernaras, Elizalde y Arrieta (2009) señalan la necesidad de reflexionar sobre la adecuación de las diferentes metodologías docentes ya que una única metodología no podría servir para todas las titulaciones, sino que hay que tener en cuenta las características específicas del alumnado. Algunas de las variables que se han relacionado con las estrategias de aprendizaje son el género, el curso (o edad) y la titulación cursada.

Según Beisser (2006), las diferencias de género en el aprendizaje existen en la mayoría de los contextos a pesar de los intentos conscientes de igualar oportunidades y resultados. En la misma línea, Lay y Kuo (2007) señalan las diferencias de género como una variable que influye en el diseño del currículum, los métodos de enseñanza, las estrategias instruccionales y los procesos de aprendizaje de los estudiantes y Adeyemi (2008) señala su papel modulador en el efecto de las estrategias de enseñanza sobre el aprendizaje.

Muchas son las investigaciones que encuentran diferencias de género en el uso de estrategias de aprendizaje (Bembenutty, 2007; Choi; McKillop; Ward y L'Hirondelle, 2006; Khalil, 2005). La investigación apunta que las mujeres hacen un mayor uso de las estrategias (Liu, 2009) y son significativamente más abiertas al uso de múltiples estrategias (Kay, 2007).

Algunas diferencias tienen que ver con la elección de las estrategias. Por ejemplo, Hickendorff, Van Putten, Verhelst y Heiser (2010) señalan que las mujeres utilizan prioritariamente estrategias escritas mientras que los hombres son más proclives a usar estrategias cognitivas y Choi, McKillop, Wardy L'Hirondelle (2006) encuentran diferencias en función del género en la elección de la ruta de aprendizaje.

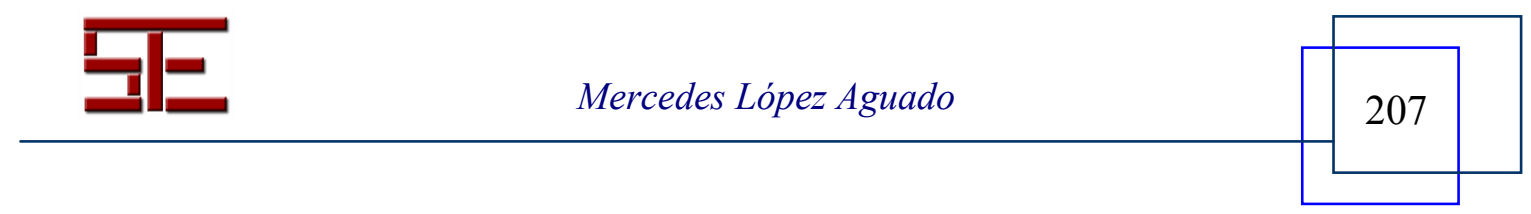




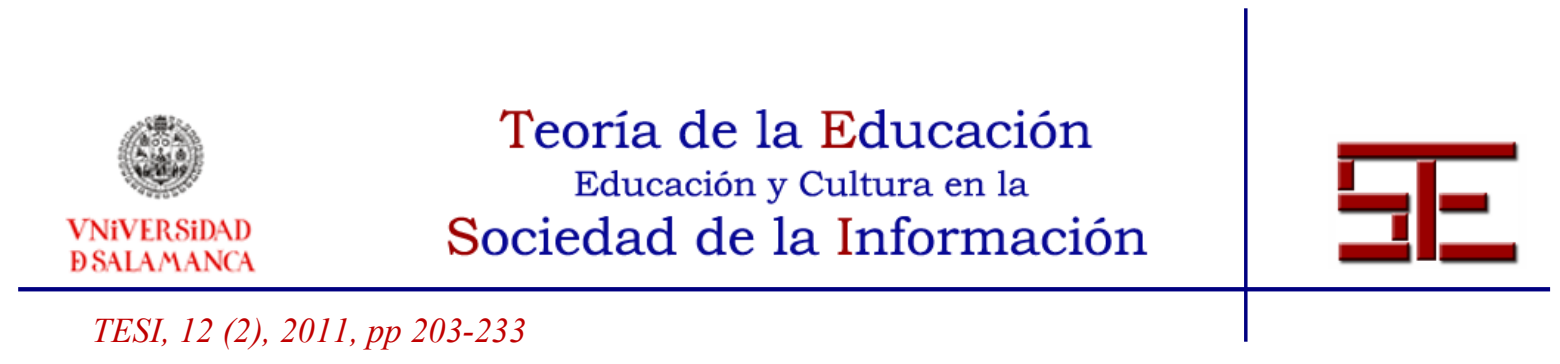

Otras investigaciones encuentran diferencias en el tipo de estrategias utilizadas en función del género. Entre otras, las mujeres usan más frecuentemente estrategias afectivas y sociales (Hong-Nam y Leavell, 2006), colaborativas (Kay, 2007), de autorregulación (Algera, 2006; Downing; Chan; Downing; Kwong y Lam, 2008; Pintrich y Zusho, 2007; Virtanen y Negvi, 2010), obtienen mayores puntuaciones en ensayo, elaboración, organización y procesamiento metacognitivo (Lynch, 2008), en estrategias para el aprendizaje de una lengua extranjera (Schueller, 2009) y hacen un uso mayor de estrategias cognitivas y metacognitivas (Clarke, 2007).

Menores son los resultados que encuentran diferencias a favor de los chicos, que parecen puntuar más alto en planificación de respuesta y respuesta escrita (Gázquez, Pérez, Ruiz, Miras y Vicente, 2006), en pensamiento crítico (Lynch, 2008) y en estrategias colaborativas y competitivas (Kolawole, 2008).

Sin embargo, también hay investigaciones que no encuentran diferencias en función de esta variable (Hong, Peng y Rowell, 2009; Nisbet, Tindall y Arroyo, 2005; PsaltouJoycey, 2008; Rodrigues, 2009; Trout, 2010; Yukselturk y Bulut, 2009), que encuentran diferencias, pero no significativas (Mok, Ma, Liu y So, 2005), con efectos de pequeño tamaño (Rodarte-Luna y Sherry, 2008) o que condicionan el efecto del género en las estrategias de aprendizaje a su papel modulador sobre la motivación (Taasoobshirazi y Carr, 2009).

Pintrich y Zusho (2007) señalan que la investigación sobre el efecto del género en las estrategias de aprendizaje no es concluyente, así como la necesidad de aclarar el papel de esta variable para que los docentes dispongan de la información adecuada de cara a ajustar su instrucción a los distintos grupos (Bembenutty, 2007).

También ha sido analizado el papel del curso (o la edad) en las estrategias de aprendizaje o, dicho de otro modo, la evolución de éstas a lo largo de la formación. Por ejemplo, Lynch (2008) encuentra que el nivel estratégico, especialmente el referido al sostenimiento del esfuerzo, disminuye en los alumnos de cursos superiores. Sin embargo, Taasoobshirazi y Carr (2009) encuentran que estar en un curso más avanzado predice directamente el mayor uso de estrategias y Gargallo (2006) señala que los estudiantes de cursos superiores utilizan estrategias más eficaces. Otros, como Leutwyler (2009), señala que desde una perspectiva global no se observan cambios en el uso de las estrategias, aunque mientras unas estrategias (como las de supervisión y

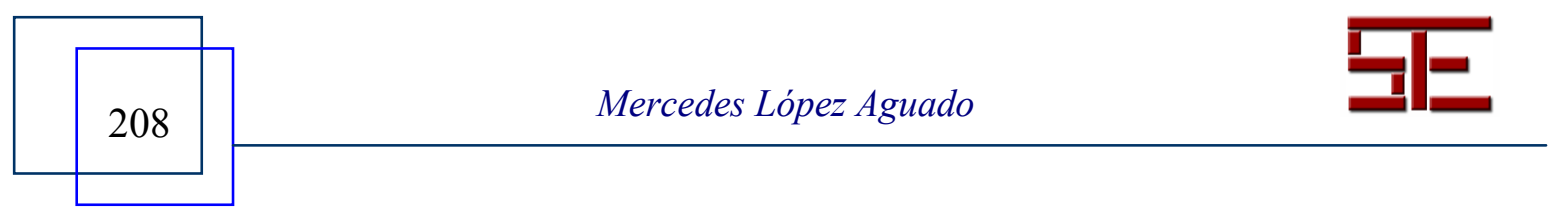




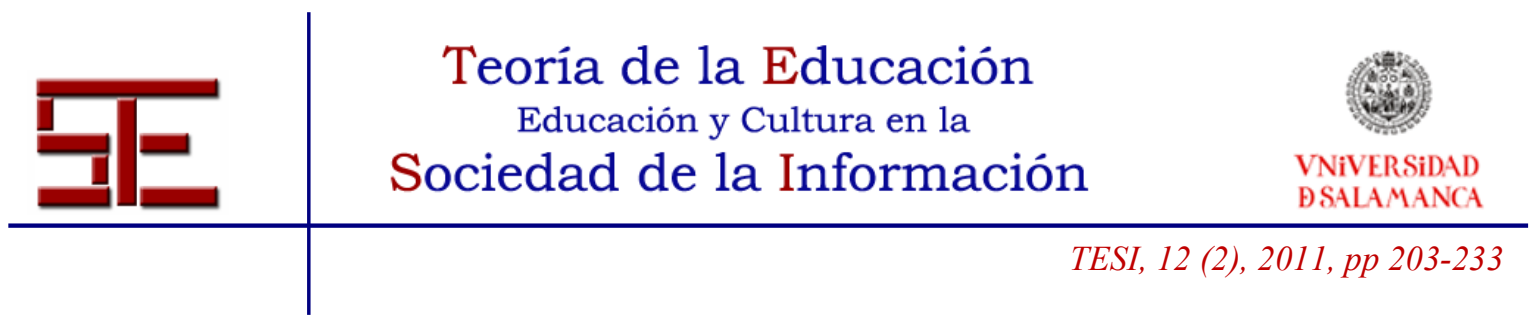

evaluación) tienden a converger entre los géneros con el paso del tiempo, otras (planificación) se mantienen constantes.

Otra de las variables que ha sido relacionada con las estrategias de aprendizaje es la disciplina o estudios cursados. La disciplina académica es una variable que incluye en muchos aspectos del proceso educativo, por ejemplo, el método instruccional utilizado prioritariamente por los docentes o el enfoque de aprendizaje de los estudiantes (Neumann; Parry y Becher, 2002; Parpala; Lindblom-Ylanne; Komulainen; Litmanen y Hirsto, 2010; Smeby, 1996).

La existencia de diferentes culturas académicas en las diferentes disciplinas también ha sido señalada por Parry (1998) en un estudio sobre escritura académica. La producción de conocimiento, así como los significados para la comunicación, varían en las diferentes disciplinas y los estudiantes aprenden tácitamente las normas de cada cultura disciplinar. En este mismo sentido, Entwistle y Tait (1995) señalan que los estudiantes de diferentes disciplinas desarrollan formas características de aprender basadas en sus percepciones de lo que se requiere en su trabajo académico y Virtanen y Negvi (2010) señalan que los estudiantes ingresan en la universidad con unas estrategias ya desarrolladas por la influencia de los profesores y culturas de aprendizaje que han encontrado en su proceso formativo, los estudiantes incrementan o disminuyen el uso de estas estrategias al recibir feedback del sistema e interpretar las normas implícitas de cada sistema de aprendizaje. También para que la disciplina produce diferencias en el conocimiento funcional, aplicación, dimensión humana y en el proceso de aprender a aprender (Levine; Fallahi; Nicoll-Senft; Tessier; Watson y Wood, 2008).

En esta línea Clayton, Blumberg y Auld (2009) relacionan las estrategias de aprendizaje con el tipo de ambiente de aprendizaje.

Aunque algunos estudios no encuentran diferencias en las estrategias en función de la disciplina (Fernández Borrás, 2006), la gran mayoría de la investigación consultada encuentra diferencias estratégicas en función de esta variable.

Así, Cooper (2009) encuentra diferencias en las estrategias en función de la disciplina y Campbell (2007), en función de la titulación. Rinaudo, De la Barrera y Donolo (2006) señalan diferencias significativas en las estrategias de alumnos de las facultades de Económicas, Ingeniería y Ciencias Humanas, encontrando perfiles estratégicos diferenciales en función de la facultad en la que se estudia. También García, Hernández

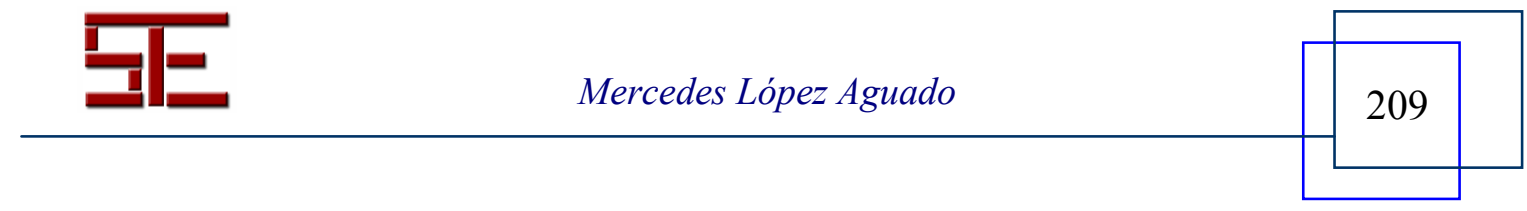




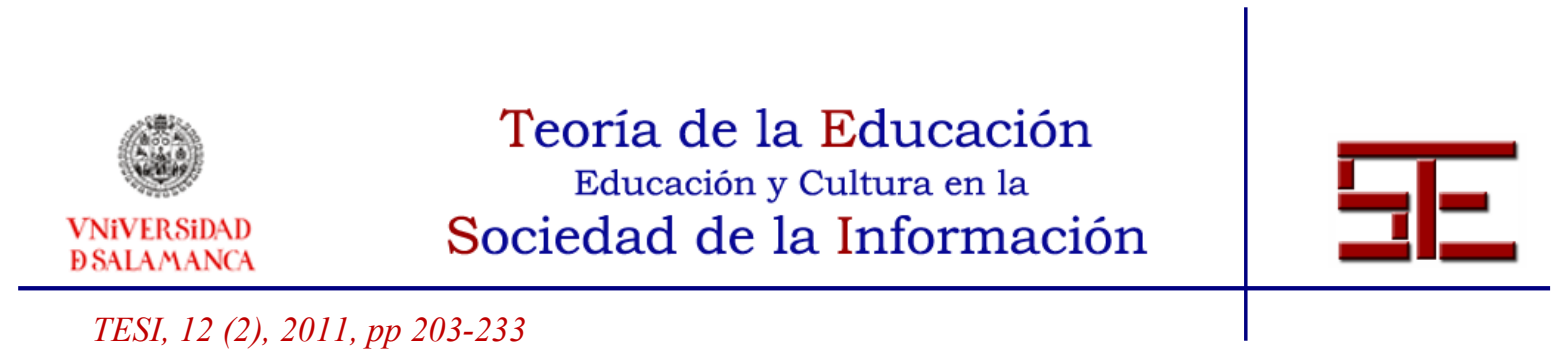

y Luján (1998) encuentran diferencias importantes en las estrategias de aprendizaje en las titulaciones analizadas, que permiten establecer un perfil específico para cada una de ellas. Gargallo (2006) encuentra diferencias en la preferencia por las distintas estrategias en función del tipo de estudios que realizan. Gil, Bernaras, Elizalde y Arrieta (2009) describen diferencias significativas en función de la titulación en las estrategias de organización y regulación metacognitiva. Ho y Hau (2008) encuentran diferencias tanto en estrategias como en otras variables relacionadas (motivación, metas y esfuerzo) en el rendimiento en diferentes materias (matemáticas e inglés).

Son menos las investigaciones que analizan el impacto de estas variables de forma conjunta (Cano, 2000), a pesar de que parece que este tipo de análisis producirá la información más relevante para su uso docente. Así, Virtanen y Nevgi (2010) encuentran que las mujeres puntúan moderadamente más alto en algunas estrategias de autorregulación y no encuentran regularidades claras en ninguna disciplina. No obstante, sí encuentran diferencias significativas al analizar de forma conjunta ambas variables: hombres y mujeres de ciencias del comportamiento y mujeres de ciencias puntúan consistentemente más alto en estrategias de autorregulación y los hombres de tecnologías obtienen las puntuaciones más bajas. Martín y Camarero (2001) también confirman la interacción significativa del género con el tipo de estudios universitarios. Consideran que las diferentes formas de abordar y procesar la información están moduladas por el tipo de contenidos curriculares y las demandas de las diversas tareas universitarias. Indican la importancia de esta interacción para comprender la naturaleza de las diferencias de género en el aprendizaje, que no se producirían tanto por razones genéticas, como por factores culturales y aspectos derivados de los contenidos específicos de cada tipo de tarea que fomentan o atenúan el uso (y, por tanto, desarrollo) de ciertos recursos intelectuales. Del mismo modo, señalan la conveniencia de considerar estos resultados con el objetivo de que el profesor impulse el desarrollo de las diferentes capacidades y estilos de aprendizaje de todos sus alumnos.

El objetivo de este trabajo es profundizar en el papel del género y la disciplina estudiada en las estrategias de aprendizaje así como la evolución de éstas a lo largo del proceso formativo de los estudiantes universitarios.

En función del análisis global de la investigación previa, es previsible encontrar diferencias por género, curso y tipo de titulación.

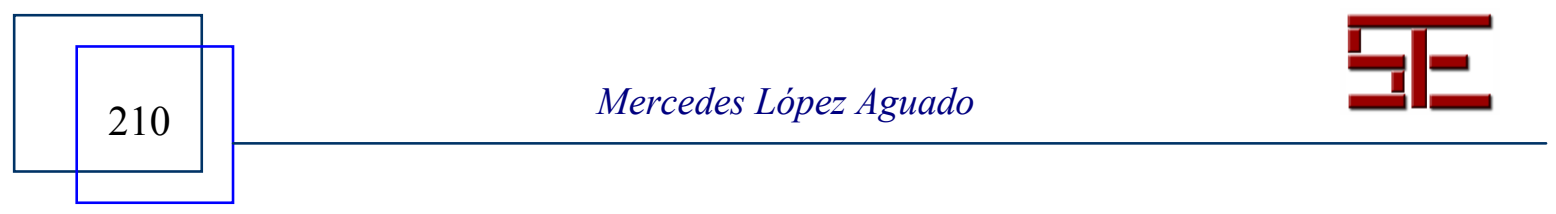




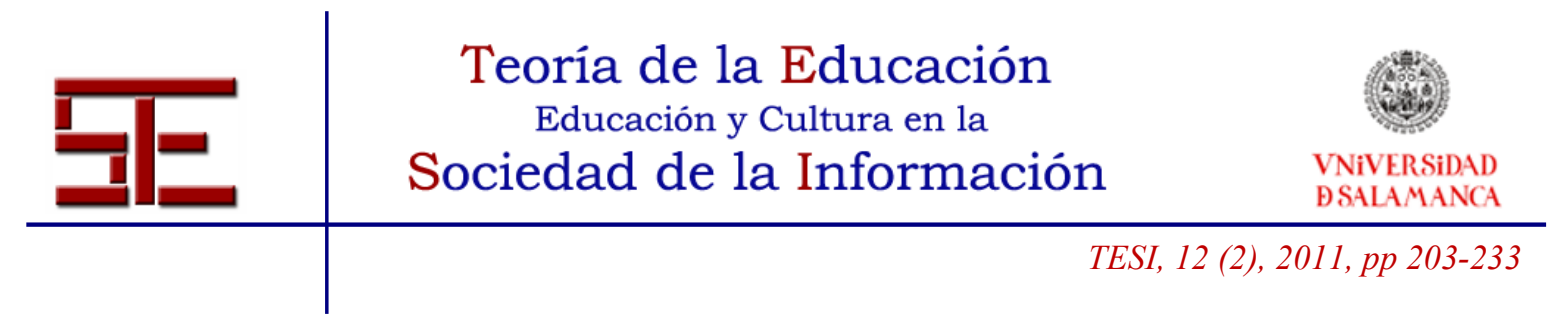

\section{2.- MÉTODO}

Para describir las estrategias de los estudiantes se realiza un diseño no experimental, sin manipulación de ninguna condición de investigación. En concreto, un diseño de encuesta en el que se recoge de forma simultánea toda la información.

\section{1.- Participantes}

Participan en el estudio 805 estudiantes de la Universidad de León de los que el 35.7\% son hombres y el 64.3\% mujeres. Estudian sus titulaciones en 8 Facultades (alumnos pertenecientes a 16 titulaciones) tal como se observa en la Tabla 1. La técnica de selección muestral es no aleatoria accidental.

Tabla 1: Distribución de la muestra por Facultades

\begin{tabular}{|l|r|r|r|r|}
\hline & Frecuencia & Porcentaje & Porcentaje válido & $\begin{array}{c}\text { Porcentaje } \\
\text { acumulado }\end{array}$ \\
\hline Filosofía & 90 & 11,2 & 11,2 & 11,2 \\
\hline Derecho & 42 & 5,2 & 5,2 & 16,4 \\
\hline Ingeniería industrial e informática & 52 & 6,5 & 6,5 & 22,9 \\
\hline Económicas y cc empresariales & 148 & 18,4 & 18,4 & 41,2 \\
\hline Biológicas & 88 & 10,9 & 8,9 & 52,2 \\
\hline Ciencias del Trabajo & 66 & 8,2 & 20,1 & 60,4 \\
\hline Educación & 162 & 20,1 & 19,5 & 80,5 \\
\hline FCAFD & 157 & 19,5 & 100,0 & 100,0 \\
\hline Total & 805 & 100,0 & \\
\hline
\end{tabular}

\section{2.- Intrumentos}

Para describir las estrategias de aprendizaje utilizadas por los estudiantes se utiliza el CETA, Cuestionario de Estrategias de Trabajo Autónomo (López-Aguado, 2010). Este cuestionario tipo Lickert consta de 45 ítems en los que se solicita al sujeto que responda, a cada uno de los reactivos comportamentales, estimando el grado de frecuencia con la que realiza cada conducta. Está compuesto de seis subescalas para cada una de las estrategias que analiza: ampliación, colaboración, conceptualización, planificación, preparación de exámenes y participación. Cada una de estas subescalas tiene como puntuación mínima 1 y máxima 5.

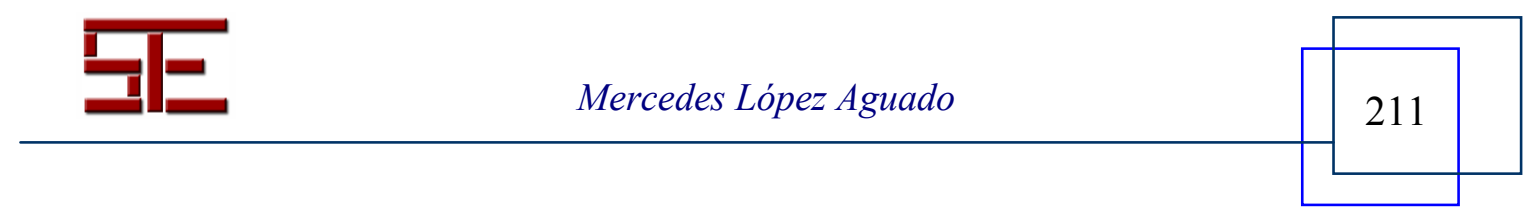




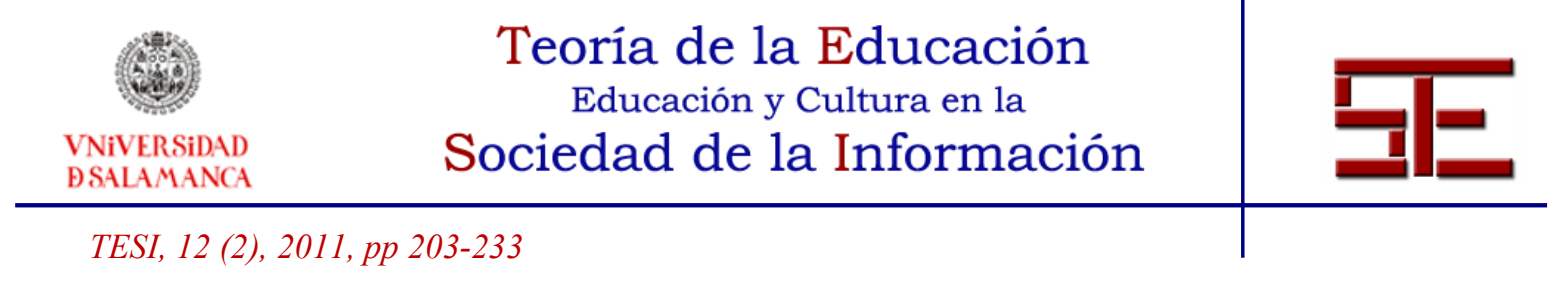

\section{3.- Procedimiento}

Se contacta con distintos profesores de las titulaciones seleccionadas y con su consentimiento y el de los alumnos que asisten a una clase normal se recogen los datos en una sesión. El tiempo de aplicación en el que se recoge simultáneamente toda la información oscila entre 20 y 30 minutos.

\section{4.- Análisis de datos}

Para la organización y el análisis de los datos se ha utilizado el SPSS (Statistical Package for the Social Sciences) en su versión 17.0. Se han realizado los siguientes análisis:

Análisis descriptivos uni y bivariados para conocer la forma en que se distribuyen las variables en la muestra.

Para determinar si existen diferencias en las estrategias en función del género, el curso y la titulación cursada se realizan análisis simples de la varianza, ANOVA.

Con el objetivo de determinar el efecto cruzado de estas variables se realiza un análisis múltiple de la varianza, MANOVA.

\section{3.- RESULTADOS}

Como se observa en la tabla de resultados, la distribución de estas variables se aproxima a la esperada, rondando las puntuaciones medias (tanto la media como la mediana ofrecen valores similares) el punto central del rango de respuestas y presentándose distribuciones relativamente simétricas, a excepción de las estrategias de preparación de exámenes que está ligeramente desviada a la derecha (-.43).

Tabla 2: Descriptivos de las estrategias en el total de la muestra

\begin{tabular}{|l|c|c|c|c|c|c|}
\hline & $\begin{array}{c}\text { Estrategias de } \\
\text { Ampliación }\end{array}$ & $\begin{array}{c}\text { Estrategias de } \\
\text { Colaboración }\end{array}$ & $\begin{array}{c}\text { Estrategias de } \\
\text { Conceptualización }\end{array}$ & $\begin{array}{c}\text { Estrategias de } \\
\text { Planificación }\end{array}$ & $\begin{array}{c}\text { Estrategias de } \\
\text { Preparación de } \\
\text { Exámenes }\end{array}$ & $\begin{array}{c}\text { Estrategias de } \\
\text { Participación }\end{array}$ \\
\hline Media & 2.58 & 3.00 & 3.26 & 2.95 & 3.58 & 3.13 \\
\hline Mediana & 2.55 & 3.00 & 3.25 & 3.00 & 3.50 & 3.17 \\
\hline Moda & 2.00 & 2.73 & 3.00 & 2.60 & 3.50 & 3.17 \\
\hline
\end{tabular}

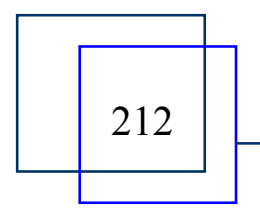




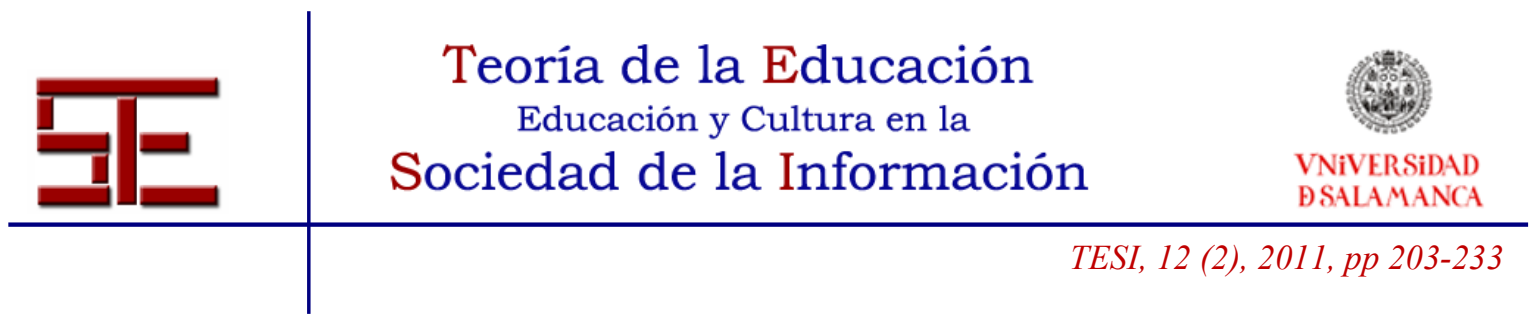

\begin{tabular}{|l|c|c|c|c|c|c|}
\hline Desv. típ. & .74 & .67 & .84 & .85 & .63 & .64 \\
\hline Asimetría & .02 & -.10 & -.19 & .05 & -.43 & .015 \\
\hline Curtosis & -.59 & -.10 & -.28 & -.50 & .66 & .31 \\
\hline
\end{tabular}

Del análisis de la distribución (Tabla 2) parece desprenderse, al menos en esta muestra, que las estrategias más utilizadas son las de preparación de exámenes seguidas de las de conceptualización. La menor puntuación (con un punto de diferencia) es la asociada a las estrategias de ampliación. Parece, pues, que los estudiantes dedican mayor esfuerzo a preparar las pruebas que a profundizar o ampliar con materiales no aportados por el docente.

Todas las estrategias de aprendizaje presentan una distribución diferencial en función del género, como se observa en la Tabla 3, excepto en el caso de las estrategias de ampliación, en el que no se aprecian diferencias en función de esta variable.

Tabla 3: Medias de las estrategias en función del género

\begin{tabular}{|l|l|c|c|c|c|c|c|}
\hline \multirow{2}{*}{ Género } & & $\begin{array}{c}\text { Estrategias } \\
\text { Ampliación }\end{array}$ & $\begin{array}{c}\text { Estrategias } \\
\text { Colaboración }\end{array}$ & $\begin{array}{c}\text { Estrategias } \\
\text { Conceptualiz }\end{array}$ & $\begin{array}{c}\text { Estrategias } \\
\text { Planificación }\end{array}$ & $\begin{array}{c}\text { Estrategias } \\
\text { Exámenes }\end{array}$ & $\begin{array}{c}\text { Estrategias } \\
\text { Participación }\end{array}$ \\
\hline \multirow{2}{*}{$\begin{array}{l}\text { Hombre } \\
\text { N } 287\end{array}$} & Media & 2.57 & 2.9 & 2.95 & 2.84 & 3.45 & 2.92 \\
\cline { 2 - 9 } & Desv. típ. & .73 & .66 & .76 & .81 & .63 & .57 \\
\hline \multirow{2}{*}{$\begin{array}{l}\text { Mujer } \\
\text { N } 518\end{array}$} & Media & 2.59 & 3.06 & 3.44 & 3.01 & 3.66 & 3.25 \\
\cline { 2 - 9 } & Desv. típ. & .75 & .68 & .84 & .87 & .61 & .65 \\
\hline \multirow{2}{*}{$\begin{array}{l}\text { Total } \\
\text { N 805 }\end{array}$} & Media & 2.58 & 3.00 & 3.27 & 2.95 & 3.58 & 3.13 \\
\cline { 2 - 9 } & Desv. típ. & .74 & .68 & .84 & .85 & .63 & .64 \\
\hline \multirow{2}{*}{$\begin{array}{c}\text { ANOVA } \\
\text { Sig. }\end{array}$} & & .735 & .002 & .000 & .006 & .000 & .000 \\
\hline
\end{tabular}

Los resultados indican que las mujeres presentan un uso más elevado de todas las estrategias. Los análisis de varianza (ANOVA) indican que estas diferencias son estadísticamente significativas (sig. <.01) en todos los casos excepto, como ya se señaló, en las estrategias de ampliación.

En relación a las diferencias estratégicas en función del curso, sólo se aprecian tendencias claras en el caso de las estrategias de ampliación. Los resultados obtenidos indican que, a medida que van aumentando de curso, disminuye el esfuerzo dirigido a ampliar contenidos y a realizar actividades nuevas o complementarias. Esta progresiva

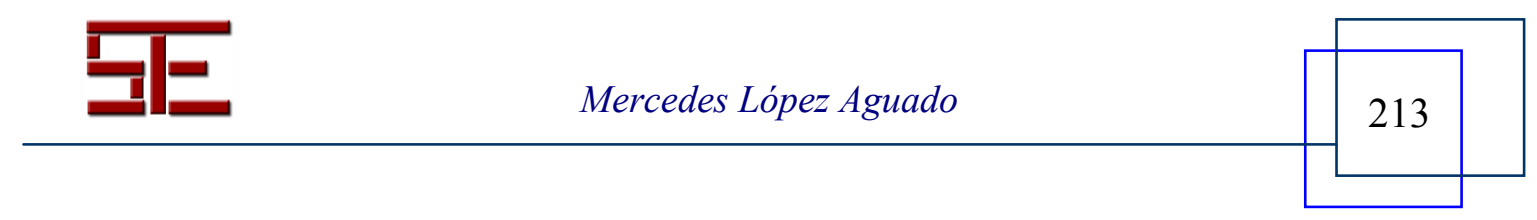




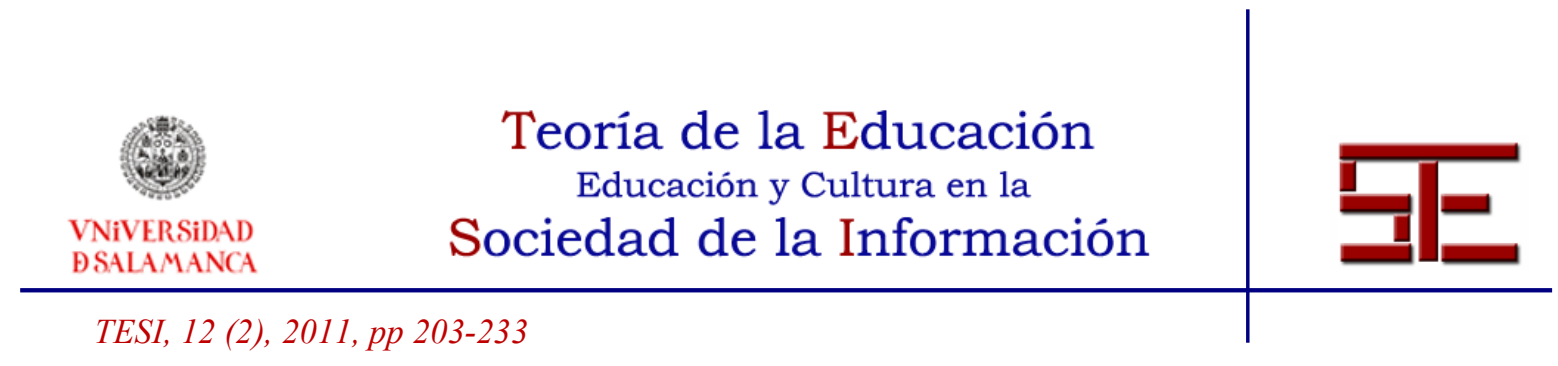

disminución de las actividades de ampliación es estadísticamente significativa (Tabla 4) y especialmente señalada entre $3^{\circ}$ y $4^{\circ}$, coincidiendo con el cambio de ciclo.

Tabla 4: Diferencias en las estrategias de ampliación en función del curso

\begin{tabular}{|l|c|c|c|}
\hline \multicolumn{1}{|c|}{ Curso } & Media & $\mathrm{N}$ & Desv. típ. \\
\hline Primero & 2.69 & 283 & .72 \\
\hline Segundo & 2.60 & 128 & .78 \\
\hline Tercero & 2.57 & 270 & .75 \\
\hline Cuarto & 2.37 & 116 & .67 \\
\hline Quinto & 2.03 & 8 & .57 \\
\hline Total & 2.5830 & 805 & .74351 \\
\hline $\begin{array}{l}\text { ANOVA } \\
\text { sig. }\end{array}$ & & & .000 \\
\hline
\end{tabular}

Para aclarar el efecto de la cultura académica o tipo de estudio se ha realizado un análisis simple de varianza, agrupando las titulaciones en tres bloques. Por un lado se dividen las titulaciones en la clásica agrupación por humanidades y ciencias, que sigue utilizándose para establecer diferencias en las estrategias y otras variables relacionadas con el aprendizaje (Webster, Chan, Prosser y Watkins, 2009) y, por otro lado, a esta clasificación se ha añadido un grupo más, ya que según Cooper (2009) se establece un clúster claramente definido para los estudiantes de Educación, de forma que tiene sentido considerarlo de forma separada.

Los resultados indican que las diferencias son estadísticamente significativas $(\mathrm{p} .<.01)$ para todas las estrategias excepto las de planificación. Los análisis post hoc (prueba de subconjuntos homogéneos) confirman las diferencias entre estas agrupaciones así como la conveniencia misma de esta clasificación.

Los resultados se recogen en la Tabla 5, en la que sólo se muestran los valores de la HSD de Tukey, obteniéndose valores paralelos para la prueba de Scheffé.

Del análisis de los grupos podemos deducir que los estudiantes de educación presentan los menores niveles en las estrategias de ampliación, niveles intermedios en estrategias de preparación de exámenes y niveles superiores al resto de agrupaciones en estrategias de colaboración (junto con los estudiantes de letras), conceptualización y participación.

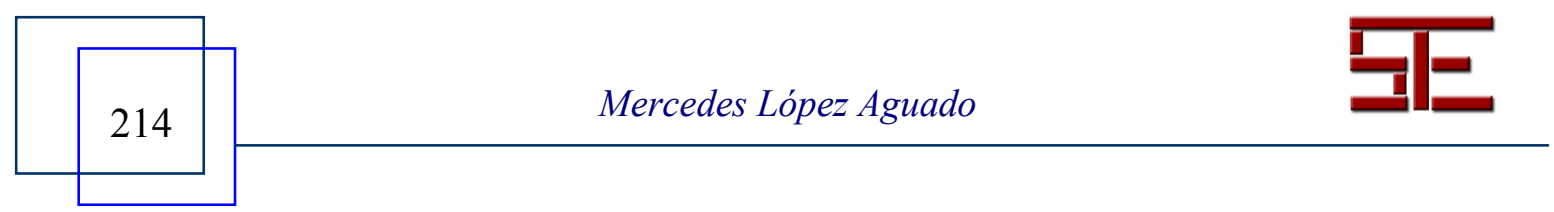




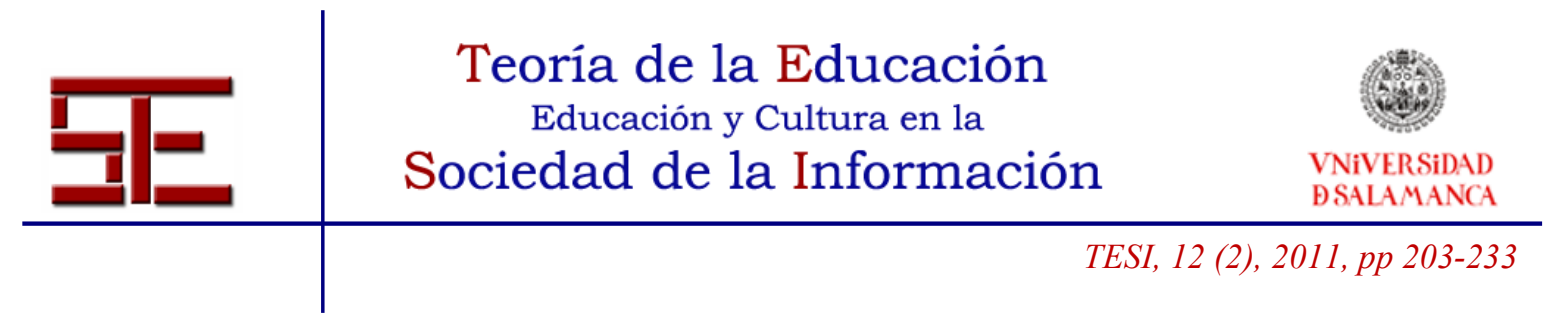

Por otro lado, los estudiantes de letras presentan los mayores niveles de estrategias de ampliación, de preparación de exámenes y de colaboración (junto con los de educación) y las menores puntuaciones en las estrategias de conceptualización y participación (con niveles similares a los estudiantes de ciencias).

Tabla 5: Prueba de subconjuntos homogéneos. Tuckey $(p<.05)$

\begin{tabular}{|c|c|c|c|c|}
\hline \multirow{2}{*}{\multicolumn{2}{|c|}{ Estrategias de ampliación }} & \multicolumn{3}{|c|}{ Subconjunto para alfa $=0.05$} \\
\hline & & 1 & 2 & 3 \\
\hline \multirow{3}{*}{ HSD de Tukey } & Educación & 2,3745 & & \\
\hline & Ciencias & & 2,5783 & \\
\hline & Letras & & & 2,7643 \\
\hline \multirow{2}{*}{\multicolumn{2}{|c|}{ Estrategias de colaboración }} & \multicolumn{2}{|c|}{ Subconjunto para alfa $=0.05$} & \\
\hline & & 1 & 2 & \\
\hline \multirow{3}{*}{ HSD de Tukey } & Ciencias & 2,9150 & & \\
\hline & Letras & & 3,1129 & \\
\hline & Educación & & 3,1178 & \\
\hline \multirow{2}{*}{\multicolumn{2}{|c|}{ Estrategias de conceptualización }} & \multicolumn{2}{|c|}{ Subconjunto para alfa $=0.05$} & \\
\hline & & 1 & 2 & \\
\hline \multirow{3}{*}{ HSD de Tukey } & Ciencias & 3,1719 & & \\
\hline & Letras & 3,2132 & & \\
\hline & Educación & & 3,6034 & \\
\hline \multirow{2}{*}{\multicolumn{2}{|c|}{ Estrategias de conceptualización }} & $\mathrm{Sb}$ alfa $=0.05$ & & \\
\hline & & 1 & & \\
\hline \multirow{3}{*}{ HSD de Tukey } & Ciencias & 2,9431 & & \\
\hline & Educación & 2,9481 & & \\
\hline & Letras & 2,9717 & & \\
\hline \multirow{2}{*}{\multicolumn{2}{|c|}{ Estrategias de preparación exámenes }} & \multicolumn{3}{|c|}{ Subconjunto para alfa $=0.05$} \\
\hline & & 1 & 2 & 3 \\
\hline \multirow{3}{*}{ HSD de Tukey } & Ciencias & 3,4708 & & \\
\hline & Educación & & 3,6379 & \\
\hline & Letras & & & 3,7983 \\
\hline \multirow{2}{*}{\multicolumn{2}{|c|}{ Estrategias de participación }} & \multicolumn{2}{|c|}{ Subconjunto para alfa $=0.05$} & \\
\hline & & 1 & 2 & \\
\hline \multirow{3}{*}{ HSD de Tukey } & Ciencias & 3,0444 & & \\
\hline & Letras & 3,1222 & & \\
\hline & Educación & & 3,3848 & \\
\hline
\end{tabular}

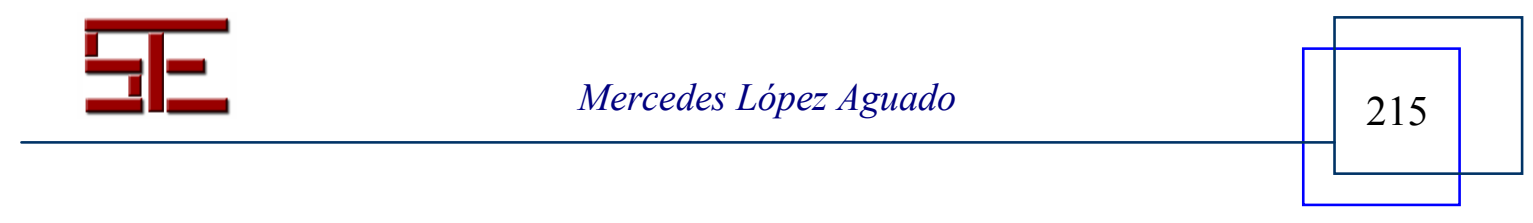




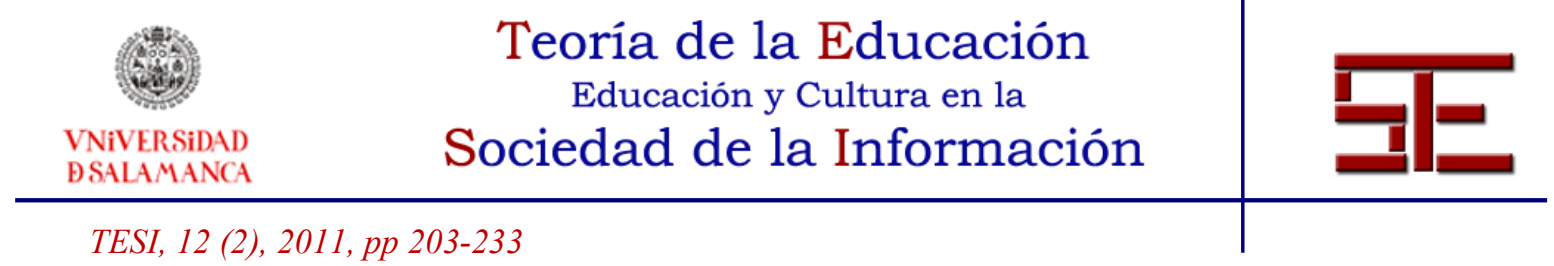

Por último, los estudiantes de ciencias presentan las menores puntuaciones en las estrategias de conceptualización, participación (con niveles similares a los estudiantes de letras), colaboración y preparación de exámenes y puntuaciones intermedias en las estrategias de ampliación. Vistos estos resultados, parece que los estudiantes de ciencias son los menos estratégicos, no sobresaliendo en el uso de ninguno de los tipos. Por otro lado, los estudiantes de letras y de educación parecen tener un mayor uso de las estrategias, especialmente los de educación.

A pesar de que las agrupaciones anteriores parecen dar buena cuenta de las diferencias, interesa conocer cómo se distribuyen las estrategias en cada una de las facultades analizadas, a fin de hacer el diagnóstico lo más cercano posible a la población diana de la intervención. La media de uso de las estrategias en función de la titulación, así como la significatividad (ANOVA) de estas diferencias se describen en la Tabla 6. Como se observa, todas son estadísticamente significativas $(\mathrm{p}<.01)$. Parece claro que, al menos en esta muestra, la formación específica que realiza el alumno determina el tipo de estrategias que utiliza.

Tabla 6: Medias de subescalas del CETA en función de la Facultad y niveles de significatividad, ANOVA

\begin{tabular}{|l|r|r|r|r|r|r|}
\hline Facultad & $\begin{array}{c}\text { Estrategias } \\
\text { Ampliación }\end{array}$ & $\begin{array}{c}\text { Estrategias } \\
\text { Colaboración }\end{array}$ & $\begin{array}{c}\text { Estrategias } \\
\text { Conceptualiza }\end{array}$ & $\begin{array}{c}\text { Estrategias } \\
\text { Planificación }\end{array}$ & $\begin{array}{c}\text { Estrategias } \\
\text { Exámenes }\end{array}$ & $\begin{array}{c}\text { Estrategias } \\
\text { Participación }\end{array}$ \\
\hline Filosofía & 2.81 & 3.02 & 3.27 & 2.81 & 3.72 & 3.18 \\
\hline Derecho & 2.97 & 3.18 & 3.50 & 3.12 & 4.10 & 3.16 \\
\hline Ingeniería & 3.0 & 2.92 & 2.89 & 2.53 & 3.35 & 2.89 \\
\hline Económicas & 2.37 & 2.83 & 3.30 & 2.92 & 3.53 & 3.03 \\
\hline Biológicas & 2.78 & 2.93 & 3.11 & 3.18 & 3.45 & 3.20 \\
\hline CC Trabajo & 2.60 & 3.25 & 2.98 & 3.14 & 3.73 & 3.08 \\
\hline Educación & 2.37 & 3.12 & 3.60 & 2.95 & 3.64 & 3.38 \\
\hline FCAFD & 2.50 & 2.95 & 3.14 & 3.00 & 3.42 & 3.00 \\
\hline Total & 2.58 & 3.00 & 3.27 & 2.95 & 3.59 & 3.13 \\
\hline ANOVA & .000 & .000 & .000 & .000 & .000 & .000 \\
\hline
\end{tabular}

Así, se observa que los alumnos que más utilizan las estrategias de ampliación son los estudiantes de Ingenierías; los que más estrategias colaborativas despliegan son los estudiantes de Ciencias del Trabajo; los estudiantes que utilizan en mayor grado las estrategias de conceptualización y participación son los de la Facultad de Educación; los

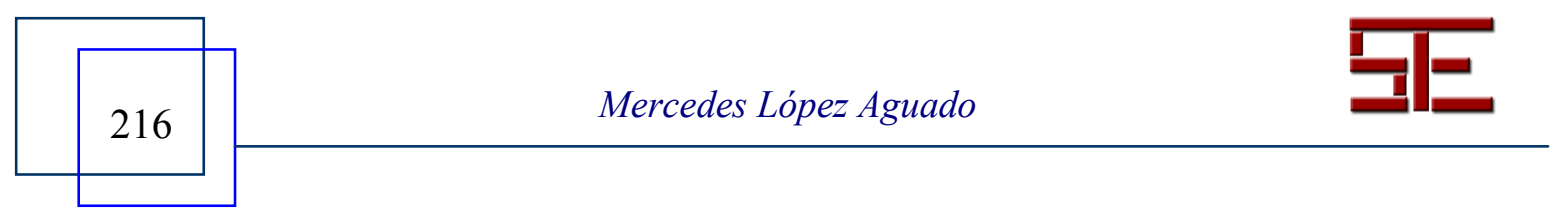




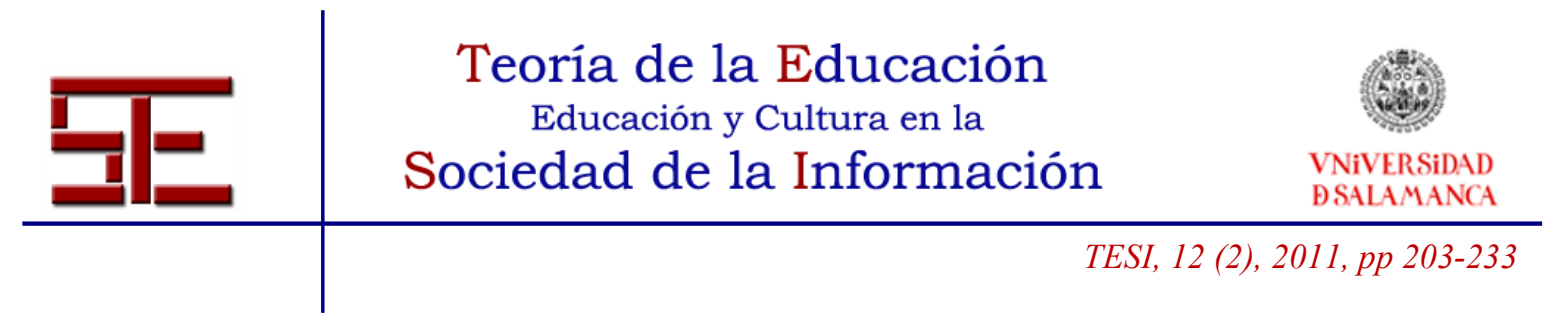

que más planifican, los alumnos de Biología, y los que dedican mayor esfuerzo a la preparación de exámenes, los estudiantes de Derecho.

Para determinar los efectos de las interacciones sobre las estrategias de aprendizaje se realiza un análisis multivariado de la varianza. Se han eliminado los 8 sujetos de quinto curso, debido a su escasa representatividad y valor en la muestra, con el objetivo de no desvirtuar los efectos relacionados con la variable curso.

Como se observa en la Tabla 7, los tres factores propuestos, género, curso y titulación, tienen efectos significativos al $99 \%(\mathrm{p}<.01)$ tanto simples como en sus interacciones excepto en el caso del curso y del cruce curso-género que siguen siendo significativos pero, en este caso, al 95\% $(\mathrm{p}<.05)$.

Tabla 7: Contrastes multivariados del Análisis Multivariante de la Varianza.

\begin{tabular}{|c|c|c|c|c|c|c|}
\hline Efecto & & Valor & $\mathrm{F}$ & $\begin{array}{c}\text { Gl de la } \\
\text { hipótesis }\end{array}$ & Gl del error & Sig. \\
\hline \multirow[t]{4}{*}{ Intersección } & Traza de Pillai & .923 & $1521.957^{\mathrm{a}}$ & 6.000 & 758.000 & .000 \\
\hline & Lambda de Wilks & .077 & $1521.957^{\mathrm{a}}$ & 6.000 & 758.000 & .000 \\
\hline & Traza de Hotelling & 12.047 & $1521.957^{\mathrm{a}}$ & 6.000 & 758.000 & .000 \\
\hline & Raíz mayor de Roy & 12.047 & $1521.957^{\mathrm{a}}$ & 6.000 & 758.000 & .000 \\
\hline \multirow[t]{4}{*}{ Curso } & Traza de Pillai & .042 & 1.783 & 18.000 & 2280.000 & .022 \\
\hline & Lambda de Wilks & .959 & 1.791 & 18.000 & 2144.433 & .021 \\
\hline & Traza de Hotelling & .043 & 1.799 & 18.000 & 2270.000 & .020 \\
\hline & Raíz mayor de Roy & .034 & $4.304^{\mathrm{b}}$ & 6.000 & 760.000 & .000 \\
\hline \multirow[t]{4}{*}{ Género } & Traza de Pillai & .036 & $4.718^{\mathrm{a}}$ & 6.000 & 758.000 & .000 \\
\hline & Lambda de Wilks & .964 & $4.718^{\mathrm{a}}$ & 6.000 & 758.000 & .000 \\
\hline & Traza de Hotelling & .037 & $4.718^{\mathrm{a}}$ & 6.000 & 758.000 & .000 \\
\hline & Raíz mayor de Roy & .037 & $4.718^{\mathrm{a}}$ & 6.000 & 758.000 & .000 \\
\hline \multirow[t]{4}{*}{ Facultad } & Traza de Pillai & .178 & 3.335 & 42.000 & 4578.000 & .000 \\
\hline & Lambda de Wilks & .832 & 3.395 & 42.000 & 3558.787 & .000 \\
\hline & Traza de Hotelling & .191 & 3.435 & 42.000 & 4538.000 & .000 \\
\hline & Raíz mayor de Roy & .100 & $10.913^{\mathrm{b}}$ & 7.000 & 763.000 & .000 \\
\hline \multirow[t]{4}{*}{ Curso * género } & Traza de Pillai & .039 & 1.688 & 18.000 & 2280.000 & .035 \\
\hline & Lambda de Wilks & .961 & 1.692 & 18.000 & 2144.433 & .034 \\
\hline & Traza de Hotelling & .040 & 1.695 & 18.000 & 2270.000 & .034 \\
\hline & Raíz mayor de Roy & .028 & $3.552^{\mathrm{b}}$ & 6.000 & 760.000 & .002 \\
\hline
\end{tabular}

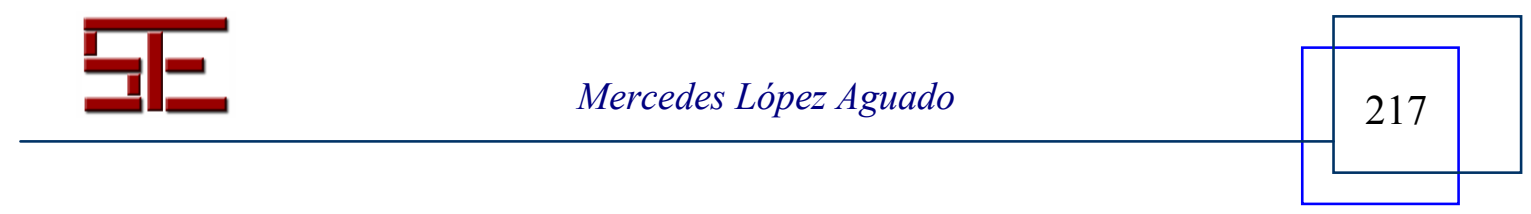




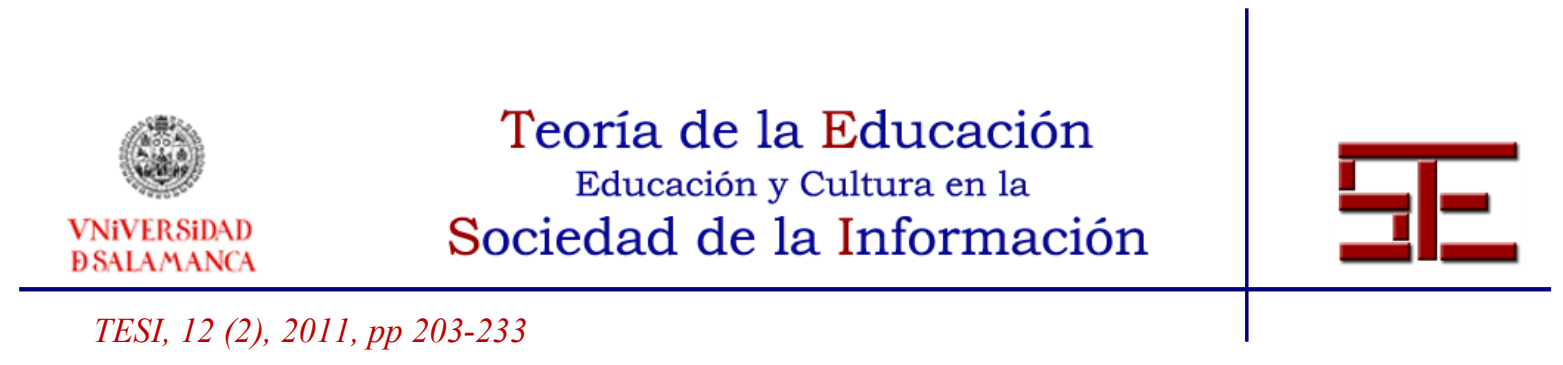

\begin{tabular}{|c|c|c|c|c|c|c|}
\hline \multirow[t]{4}{*}{ Curso * facultad } & Traza de Pillai & .152 & 2.473 & 48.000 & 4578.000 & .000 \\
\hline & Lambda de Wilks & .856 & 2.491 & 48.000 & 3733.740 & .000 \\
\hline & Traza de Hotelling & .159 & 2.501 & 48.000 & 4538.000 & .000 \\
\hline & Raíz mayor de Roy & .070 & $6.714^{b}$ & 8.000 & 763.000 & .000 \\
\hline \multirow[t]{4}{*}{ Género * facultad } & Traza de Pillai & .142 & 2.644 & 42.000 & 4578.000 & .000 \\
\hline & Lambda de Wilks & .864 & 2.672 & 42.000 & 3558.787 & .000 \\
\hline & Traza de Hotelling & .149 & 2.690 & 42.000 & 4538.000 & .000 \\
\hline & Raíz mayor de Roy & .078 & $8.480^{b}$ & 7.000 & 763.000 & .000 \\
\hline \multirow{4}{*}{$\begin{array}{l}\text { Curso } * \text { género } \\
\text { facultad }\end{array}$} & * Traza de Pillai & .097 & 3.138 & 24.000 & 3044.000 & .000 \\
\hline & Lambda de Wilks & .905 & 3.185 & 24.000 & 2645.556 & .000 \\
\hline & Traza de Hotelling & .102 & 3.225 & 24.000 & 3026.000 & .000 \\
\hline & Raíz mayor de Roy & .076 & $9.678^{b}$ & 6.000 & 761.000 & .000 \\
\hline
\end{tabular}

Los efectos de estas variables, sus interacciones y las representaciones gráficas de las medias marginales para cada una de las estrategias se describen a continuación. Se exceptúan las representaciones gráficas del cruce curso * titulación por no haber sujetos en todos los cruces.

\subsection{Estrategias de ampliación}

Como se observa en la Gráfica 1, las estrategias de ampliación se distribuyen diferencialmente si tenemos en cuenta los efectos de la interacción entre las variables, aunque sólo resulta significativo estadísticamente el efecto del curso combinado con la facultad en la que se estudia.

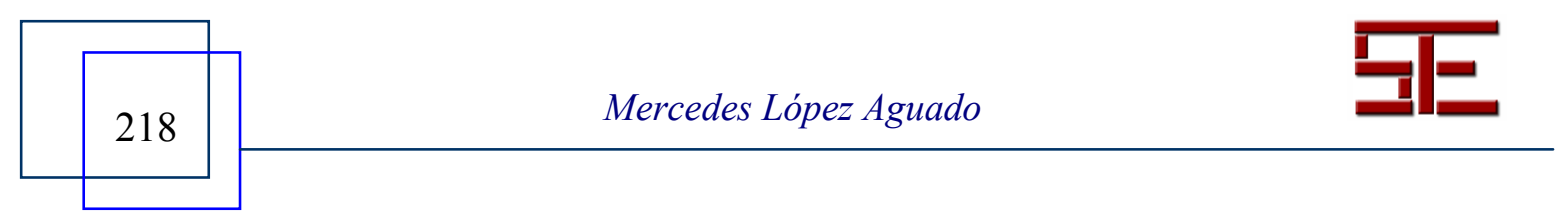




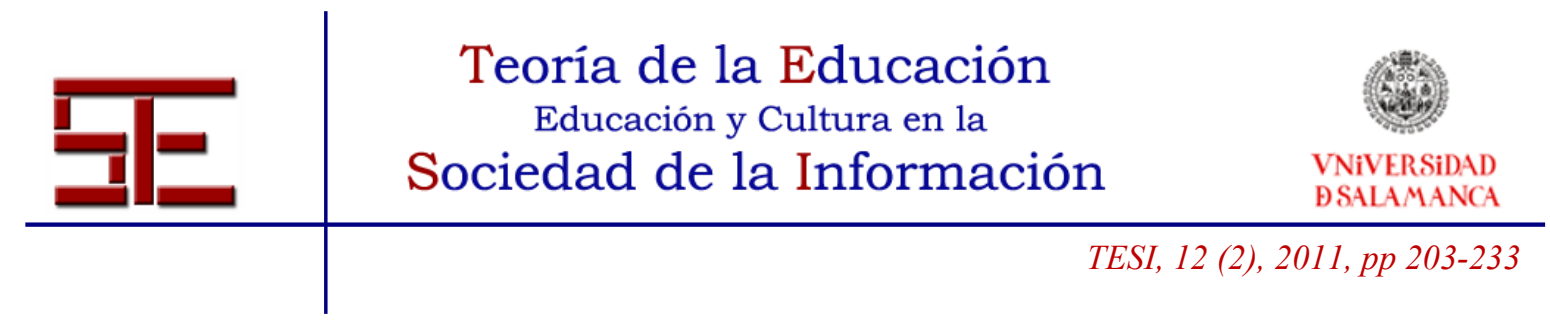

Gráfica 1: Distribución de las estrategias de ampliación en función del género, curso y facultad

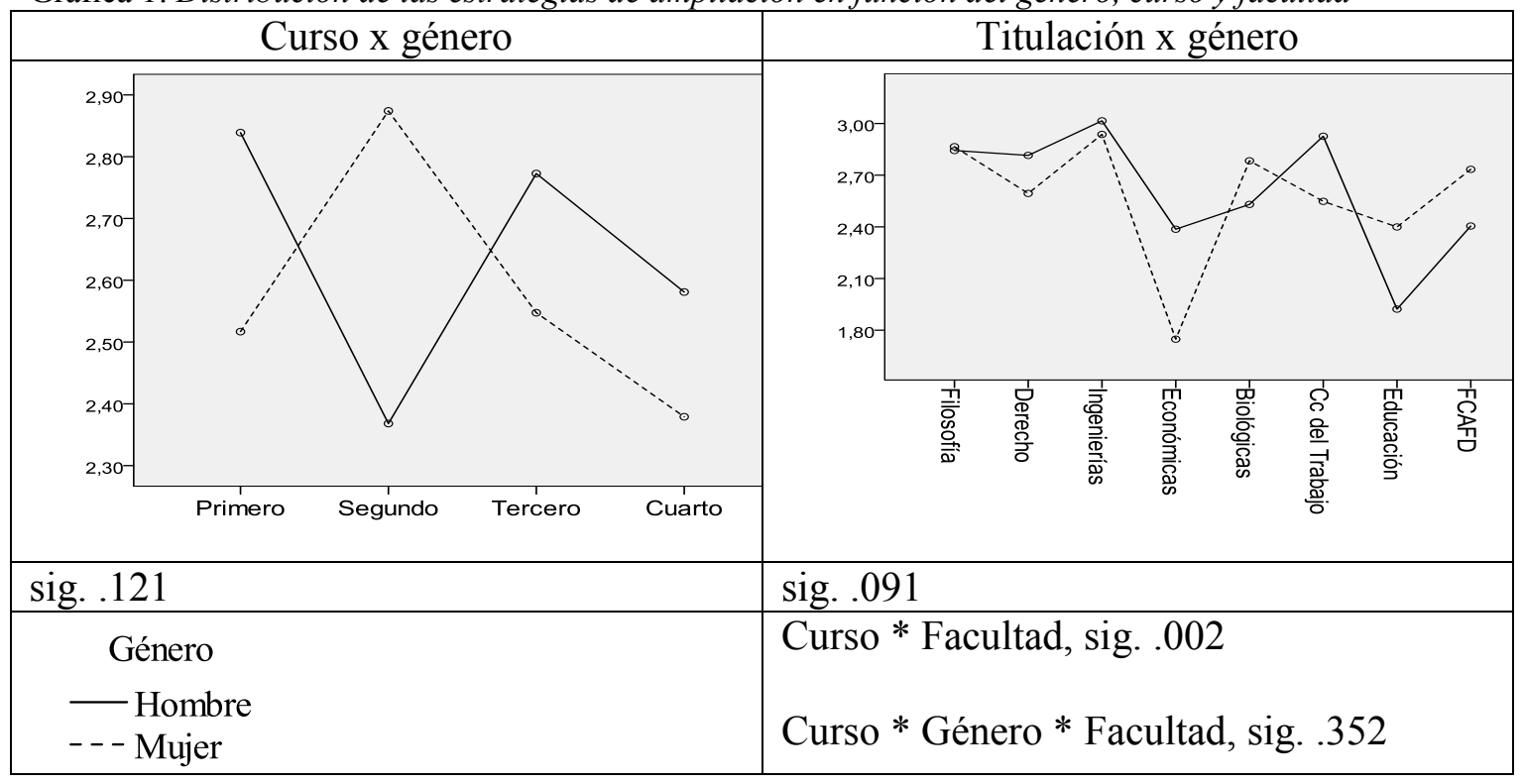

\subsection{Estrategias de colaboración}

En el caso de las estrategias de colaboración se observa (gráfica 2) cómo las diferencias debidas al género están moduladas por la titulación estudiada. De hecho, a pesar de que en el total de la muestra las mujeres presentan una superioridad estadísticamente significativa en el uso de este tipo de estrategias, esta ventaja de las mujeres sólo se produce en tres de las ocho titulaciones analizadas: Derecho, Educación y Ciencias de la Actividad Física y el Deporte (FCAFD). Los estudiantes más colaborativos son los hombres de Ciencias del Trabajo y las que menos las mujeres de Económicas.

También se aprecia el efecto conjunto del género y el curso. Parece que en primero son los hombres los que utilizan más este tipo de estrategias (siendo las mujeres de primero las que obtienen las menores puntuaciones). Esta situación se iguala en segundo, curso a partir del que los hombres comienzan a incrementar de forma progresiva su uso, produciéndose una tendencia similar en ambos géneros.

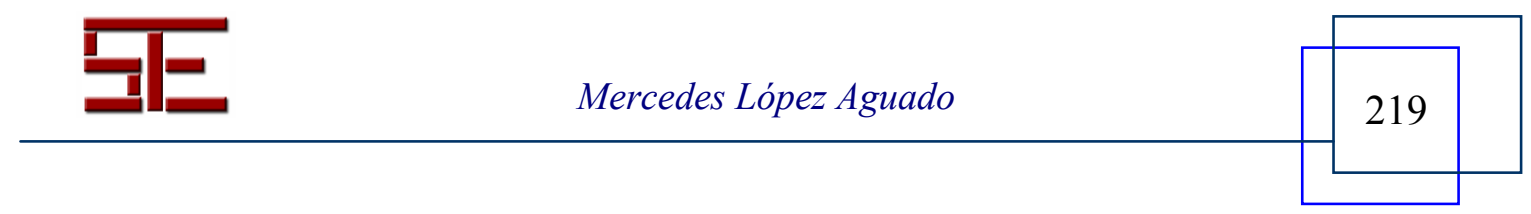


Gráfica 2: Distribución de las estrategias de colaboración en función del género, curso y facultad

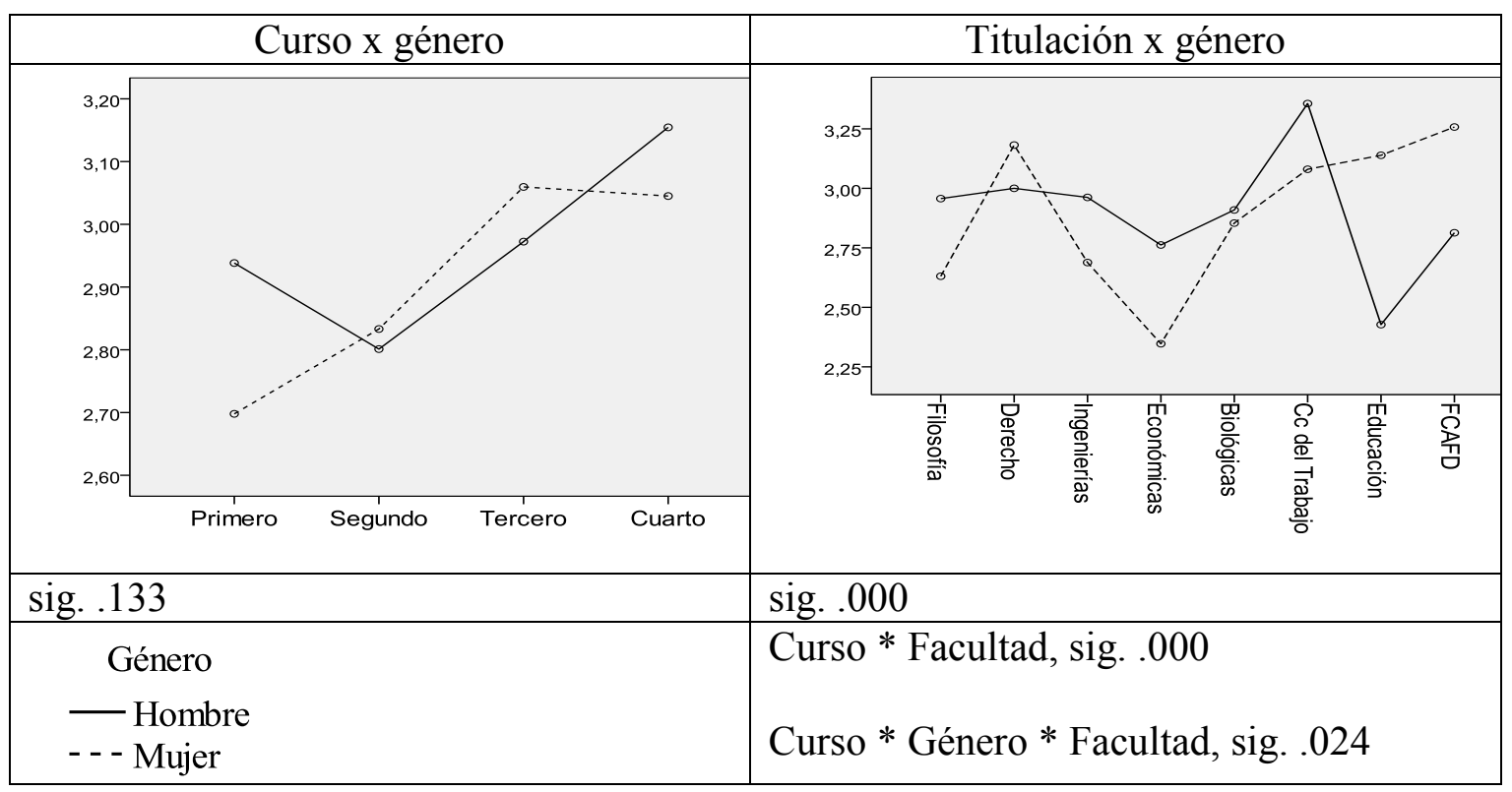

\subsection{Estrategias de conceptualización}

En cuanto a las estrategias de conceptualización, también se aprecian diferencias llamativas cuando se ponen en relación género y titulación estudiada. Parece que tanto hombres como mujeres utilizan de forma similar este tipo de estrategias en Filosofía, Ingeniería, Económicas, Biológicas y Ciencias del Trabajo (gráfica 3). Sin embargo, se aprecian grandes diferencias de uso, a favor de las mujeres, en Educación (a cuyas mujeres corresponde el uso más elevado, y a los hombres el menor de toda la muestra), Derecho y Ciencias de la Actividad Física y el Deporte (FCAFD).

Respecto al cruce curso-género en segundo se produce un gran desequilibrio en el uso de estas estrategias, mientras que en el resto de los cursos el uso de estas estrategias es más equiparable en los dos géneros.

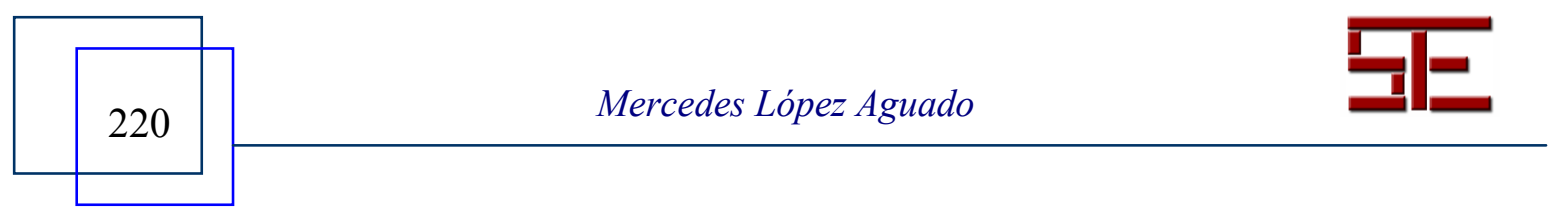




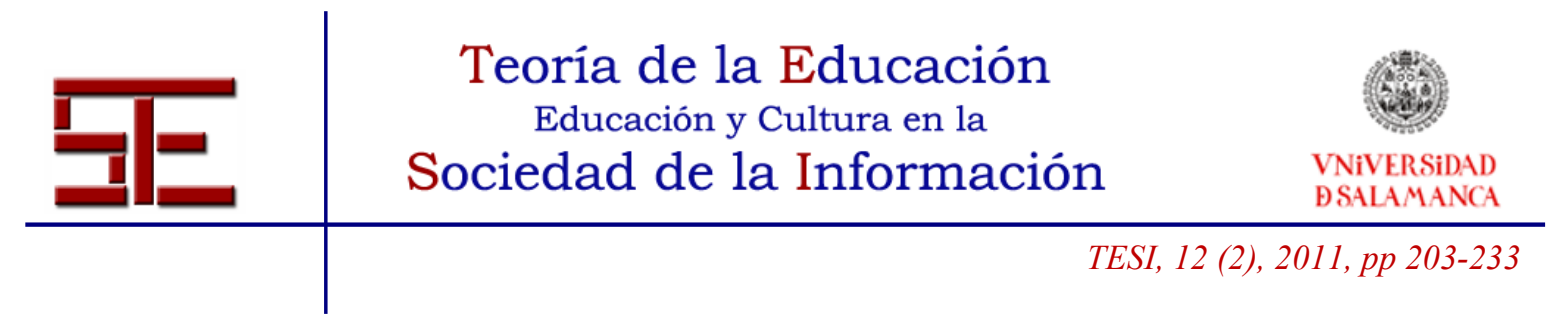

Gráfica 3: Distribución de las estrategias de conceptualización en función del género, curso y facultad

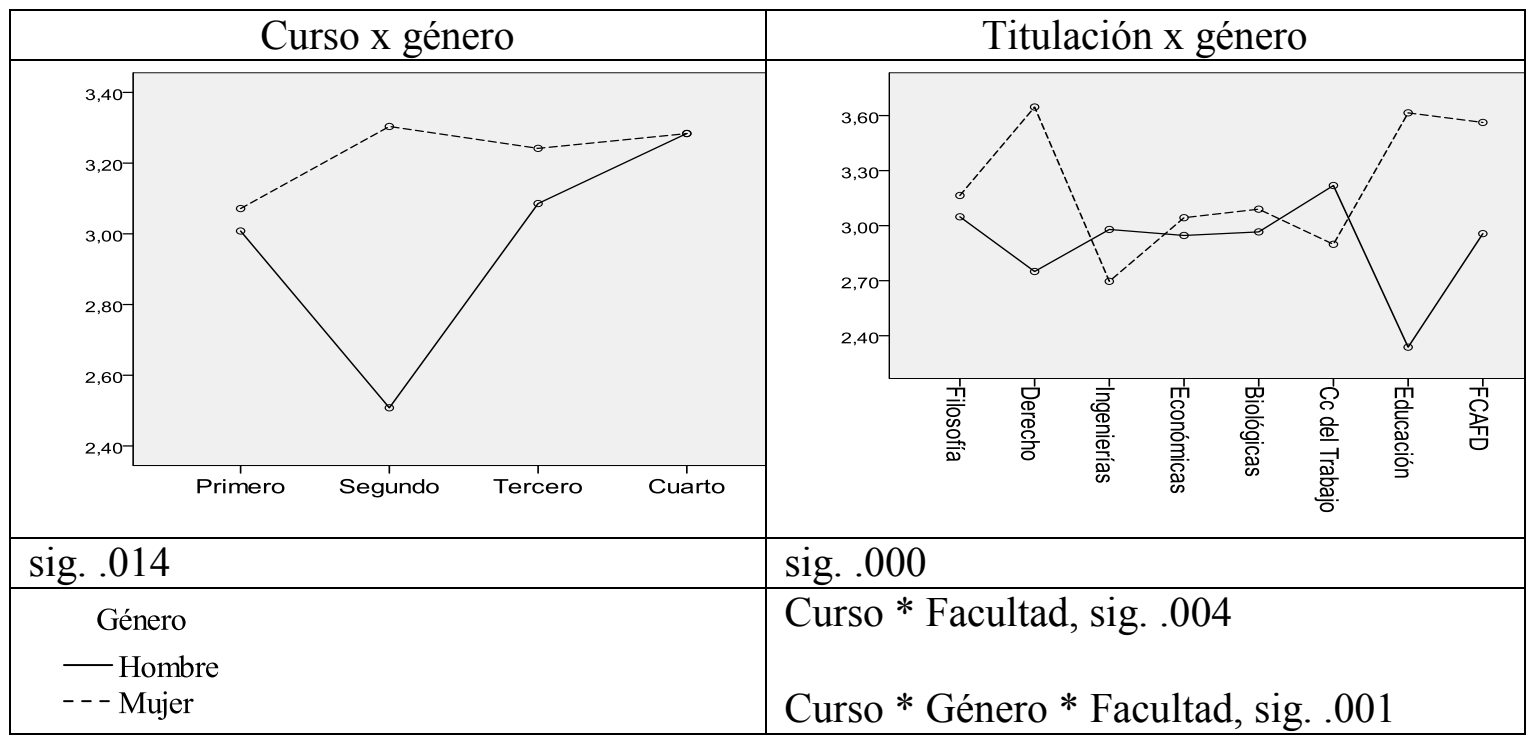

\subsection{Estrategias de planificación}

De nuevo se aprecia el efecto modulador de la titulación en la relación que se establece entre las estrategias y el género (gráfica 5). El grupo que más utiliza este tipo de estrategias son los hombres de Derecho y el que menos (en el que además se produce la mayor diferencia relativa respecto a las mujeres) es el de hombres de Educación. Para el resto de estudios, a excepción de Filosofía, las diferencias son menos significativas.

Los estudiantes que más planifican parecen ser los hombres de primero $\mathrm{y}$, los que menos, de forma llamativa, los hombres de segundo.

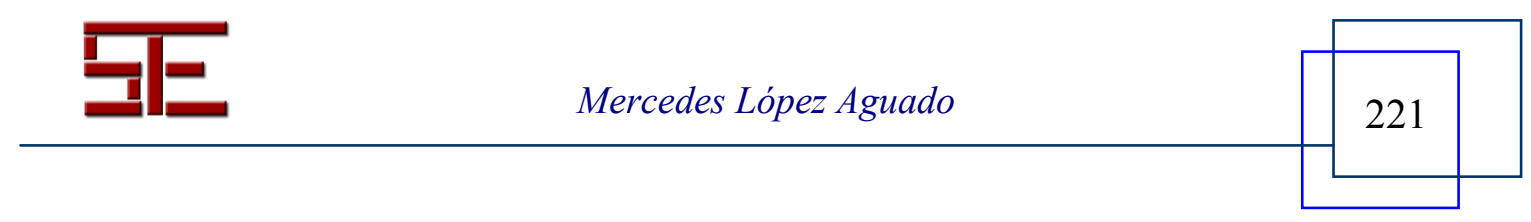


Gráfica 5: Distribución de las estrategias de planificación en función del género, curso y facultad

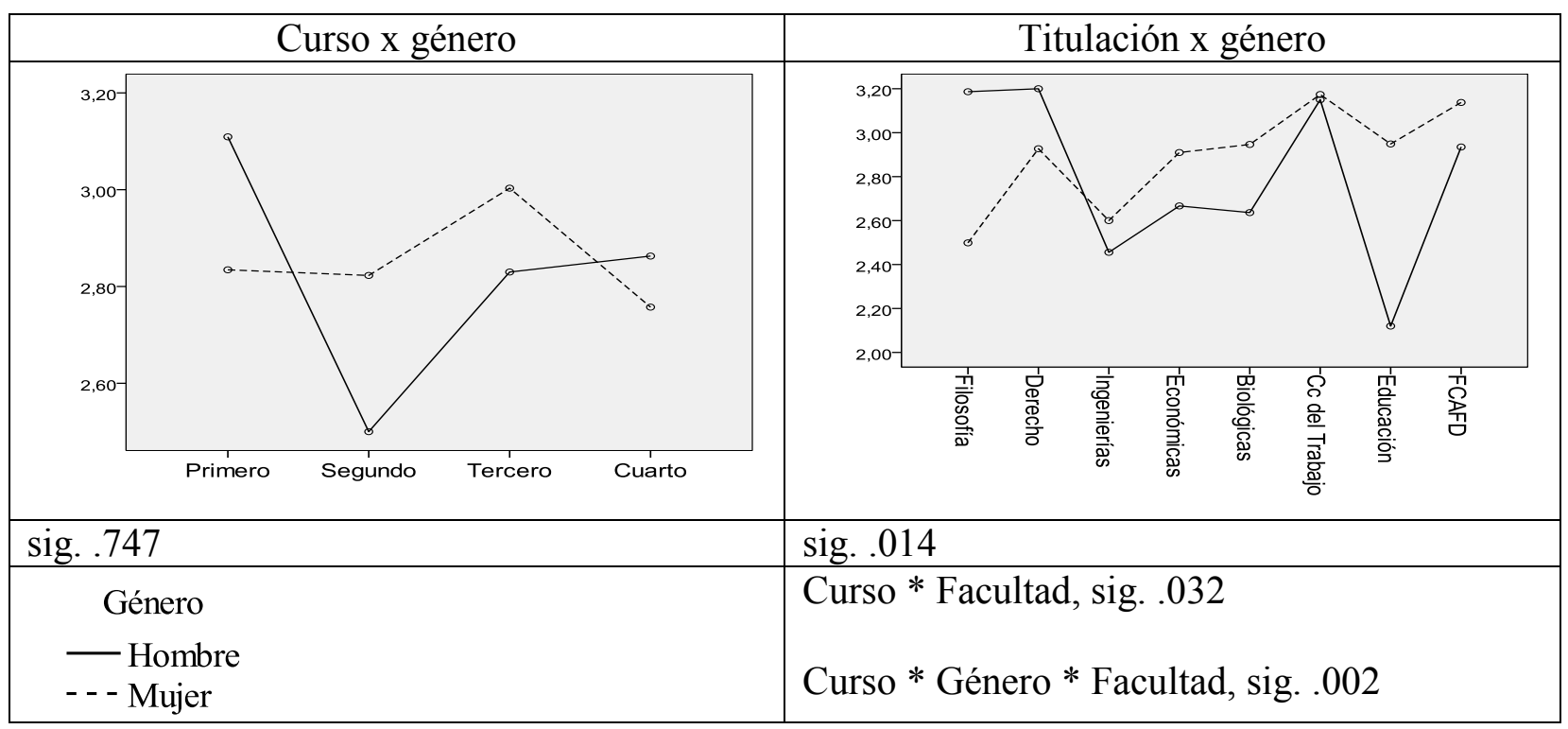

\subsection{Estrategias de preparación de exámenes}

En la representación gráfica (gráfica 6) se observa un gran paralelismo (con las excepciones que se comentan) en el cruce titulación-género, lo que indica que hombres y mujeres presentan un uso similar de las estrategias de preparación de exámenes en cada una de las titulaciones a excepción de Ciencias de la Actividad Física y el Deporte (FCAFD) y Educación. En éstas últimas se produce las mujeres parecen utilizar más este tipo de estrategias, siendo la diferencia especialmente llamativa en el caso de Educación.

Por otro lado, a excepción de primero, las mujeres presentan una tendencia creciente en estas estrategias a lo largo de los cursos, siempre por encima de las puntuaciones de los hombres.

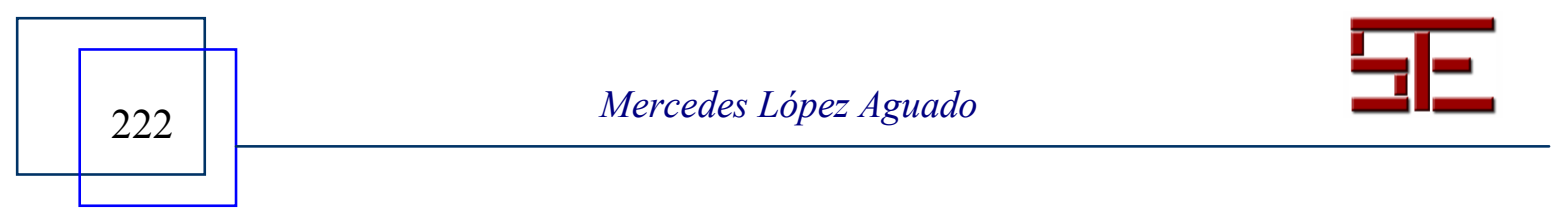




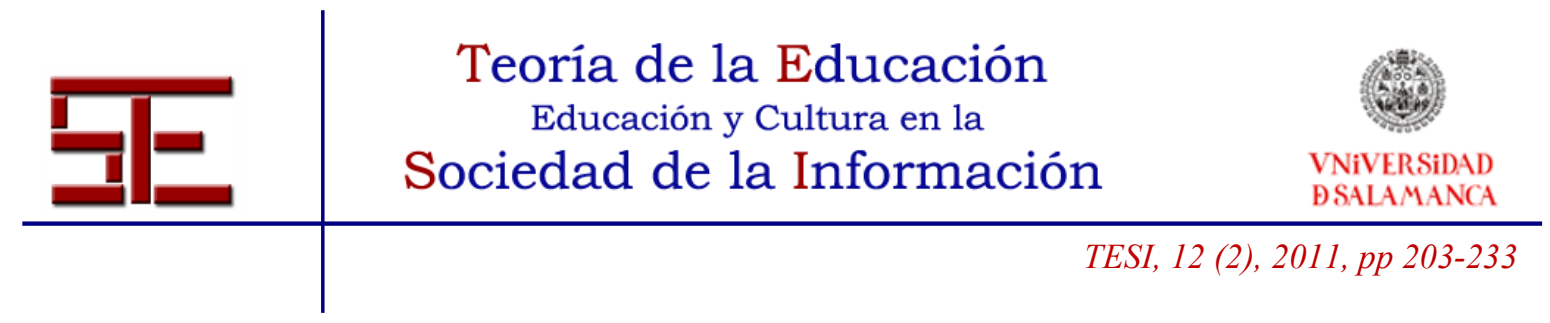

Gráfica 6: Distribución de las estrategias de preparación de exámenes en función del género, curso y facultad

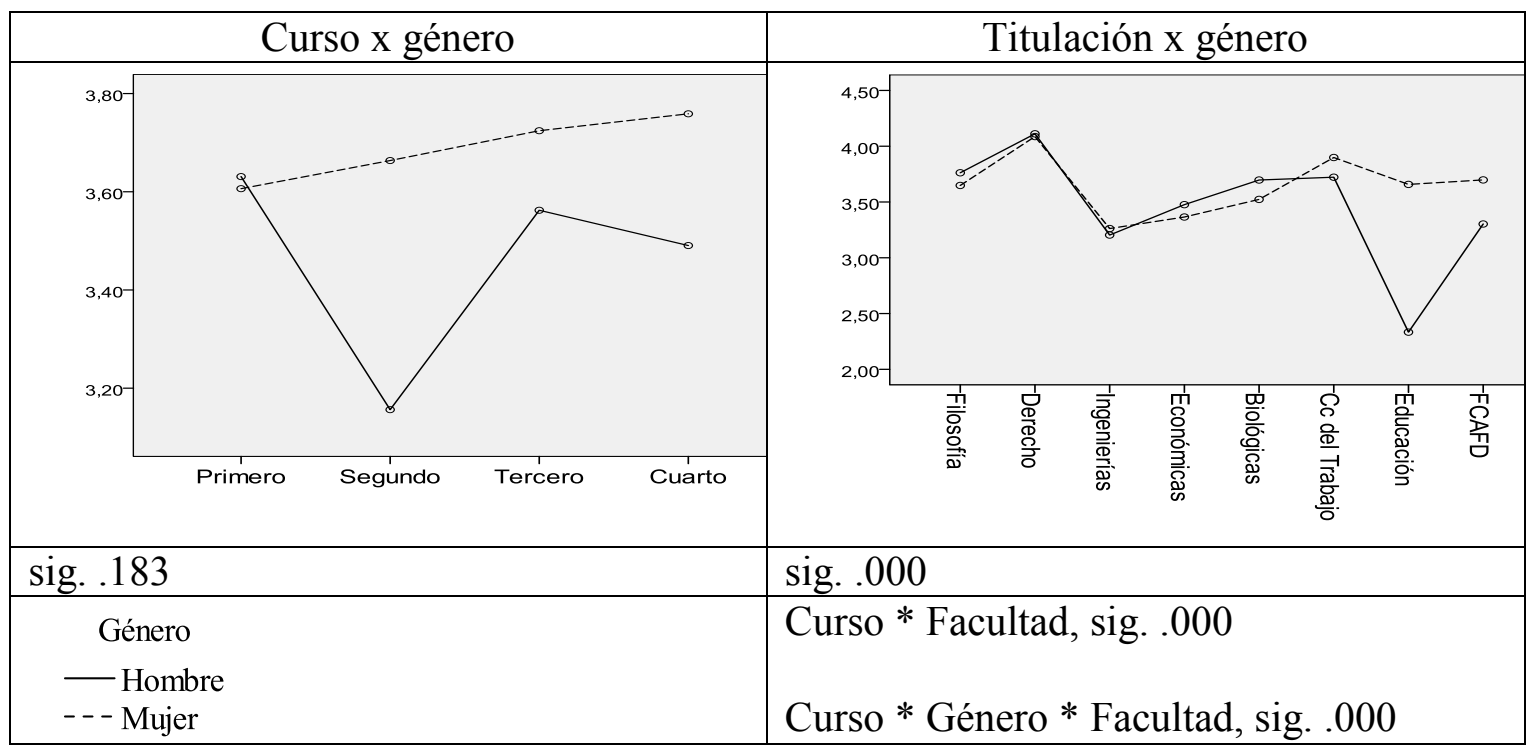

\subsection{Estrategias de participación}

Parece que las mujeres sobresalen de forma manifiesta en las estrategias de participación (excepto en Ciencias del Trabajo, en el que los hombres puntúan por encima, y en el de Filosofía, en el que ambos grupos están igualados) siendo las diferencias especialmente llamativas en el caso de Económicas y Educación

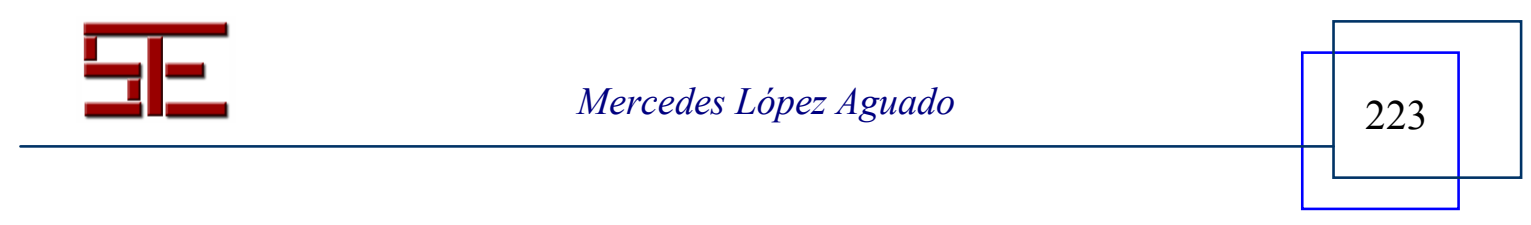




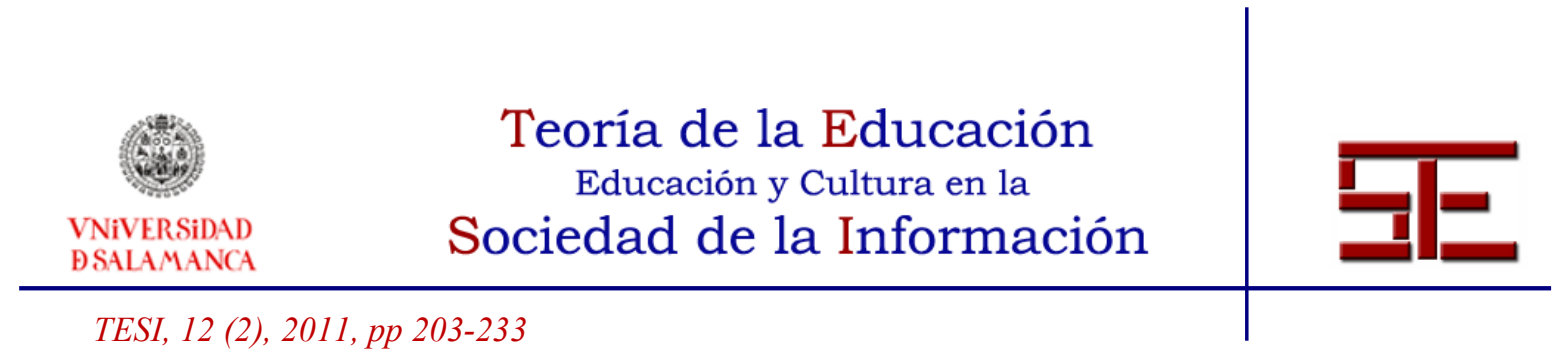

Gráfica 7: Distribución de las estrategias de participación en función del género, curso y facultad

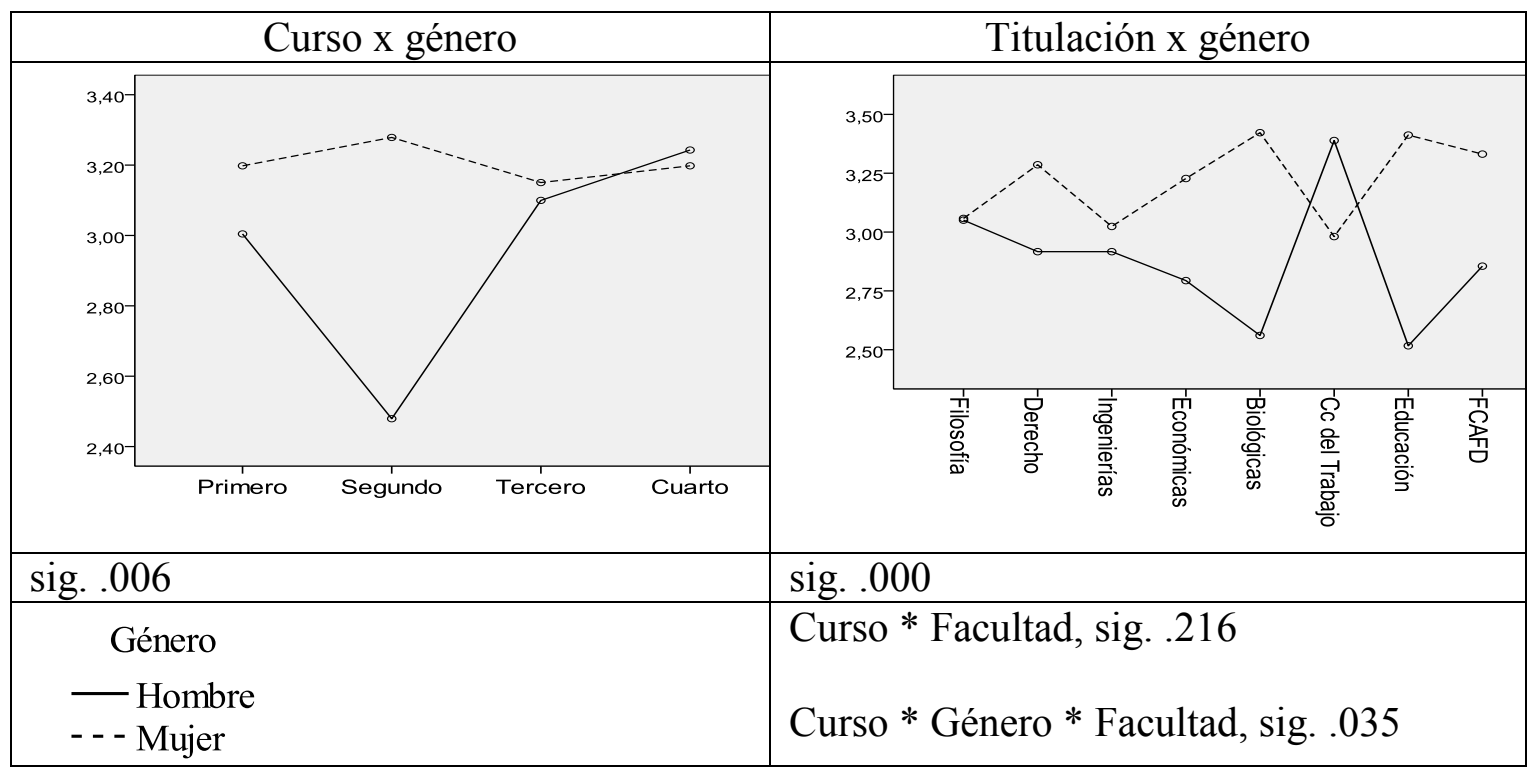

También se aprecia el efecto del cruce entre género y curso. En los dos primeros cursos, especialmente en segundo, las mujeres obtienen las mayores puntuaciones, estas diferencias se igualan a partir de tercero (gráfica 7).

\section{4.- DISCUSIÓN}

La descripción de la distribución de las estrategias confirma, de forma general, las hipótesis propuestas.

Analizando el efecto individual de las variables, encontramos que el género produce diferencias significativas en el uso de todos los tipos de estrategias (excepto en la de ampliación), siendo éste siempre superior en las mujeres, resultados concordantes con otras investigaciones previas (Algera, 2006; Downing; Chan; Downing; Kwong y Lam, 2008; Hong-Nam y Leavell, 2006; Kay, 2007; Liu, 2009; Pintrich y Zusho, 2007; Virtanen y Negvi, 2010; entre otros).

La variable que menos parece incidir de manera individual es el curso, tendencia similar a la encontrada por Leutwyler (2009) y contradictoria a los resultados obtenidos en otras investigaciones (Gargallo, 2006; Taasoobshirazi y Carr, 2009). El aumento de curso

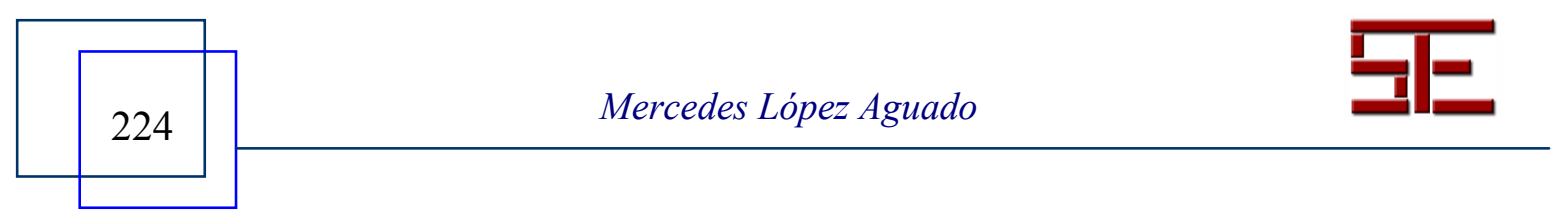




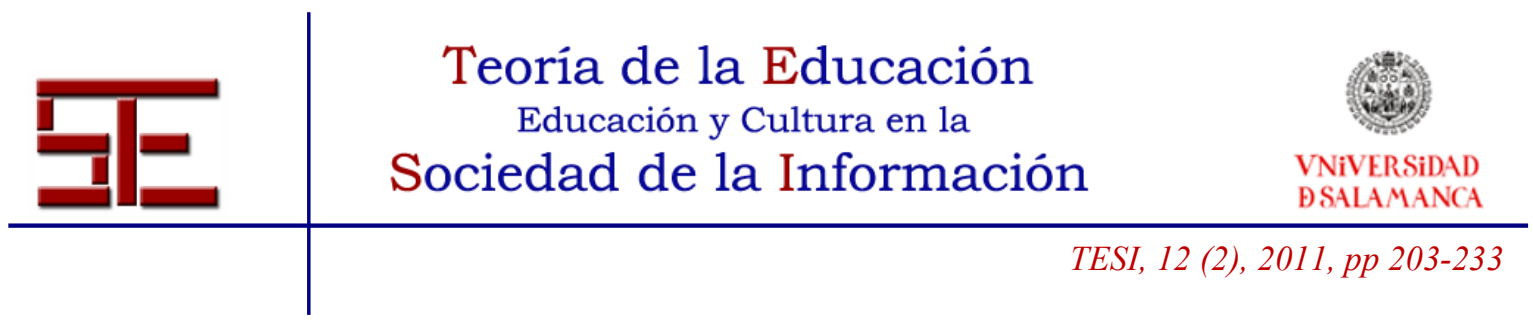

sólo parece afectar al uso de las estrategias de ampliación disminuyendo su utilización a medida que se incrementa el curso. Estos resultados parecen ir en la línea de los presentados por Lynch (2008) quien señala que el nivel estratégico, especialmente el referido al sostenimiento del esfuerzo, disminuye en los alumnos de cursos superiores.

La titulación produce diferencias significativas en el uso de todos los factores estratégicos cuando se analizan sus efectos de forma individual, resultados que confirman los obtenidos en otras investigaciones (Campbell, 2007; Cooper, 2009; García; Hernández y Luján, 1998; Gargallo, 2006; Gil; Bernaras; Elizalde y Arrieta, 2009; Ho y Hau, 2008; Rinaudo; De la Barrera y Donolo, 2006). Los grupos determinados para esta variable, permiten determinar perfiles específicos tanto por titulaciones como por grupos de ellas. Así, parece que los estudiantes de Educación, que se confirman como grupo con características propias, son los que alcanzan las mayores puntuaciones en colaboración, conceptualización y participación. Los estudiantes de letras presentan las mayores puntuaciones en conceptualización y participación y, por último, parece que los estudiantes de ciencias son los menos estratégicos de los tres grupos, al menos en esta muestra.

Sin embargo, la influencia de estas variables se ve matizada cuando se analiza los efectos de la interacción de las variables. El efecto conjunto de las tres variables propuestas explica de forma satisfactoria las variaciones en todas las estrategias propuestas excepto las de ampliación.

Así, mientras que los resultados del efecto del género tomado de manera individual presentan una clara predominancia estratégica de las mujeres sobre los hombres, si se analizan estas diferencias contextualizadas en función de la titulación, se observa que esta tendencia general no es común para todos los estudios.

Por ejemplo, en Filosofía, sólo se encuentran diferencias de género en las estrategias de colaboración y de planificación y en el sentido contrario al analizar el género individualmente, obteniendo los hombres mayores puntuaciones. Similares el caso de Ciencias del Trabajo, titulación en la que, cuando se producen diferencias, son a favor de los hombres. En otras titulaciones, sin embargo, sí se reproduce esta superioridad de las mujeres en todas las estrategias analizadas, como en Educación y Ciencias de la Actividad Física y el Deporte, aunque con diferencias entre ambas.

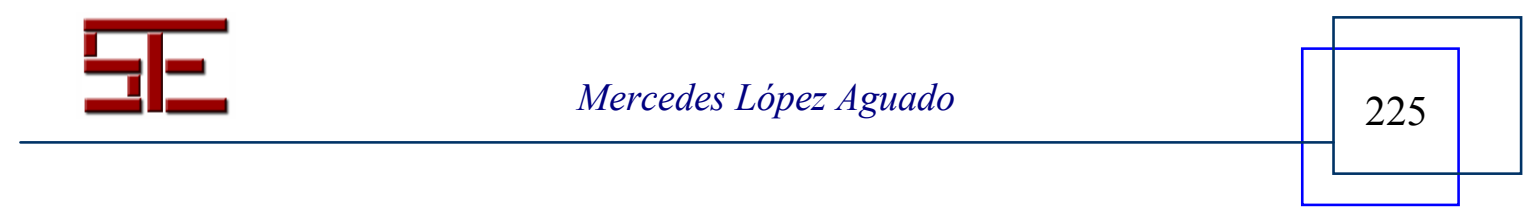




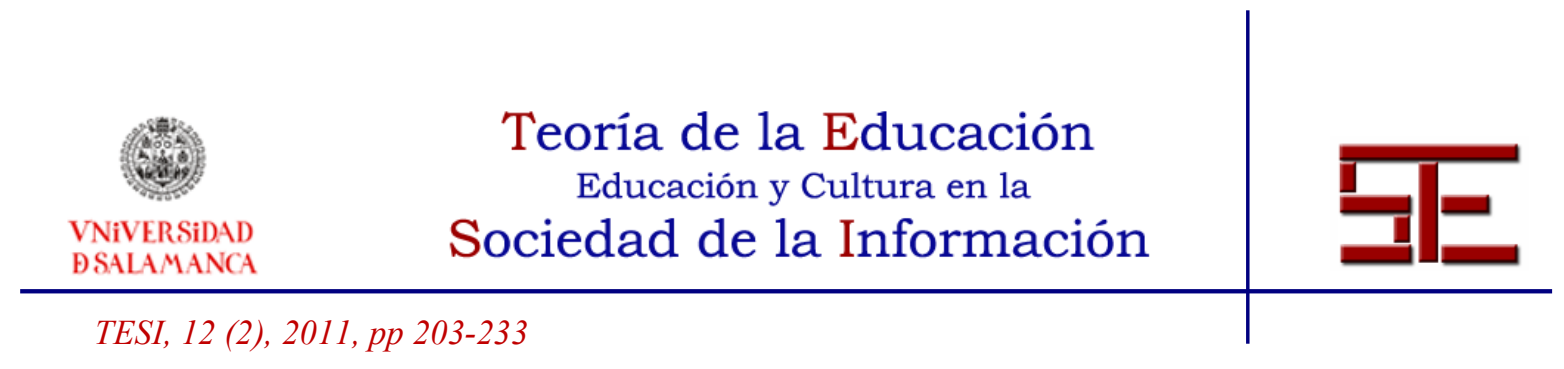

Por último, en otras facultades (Derecho, Ingenierías, Económicas, Biológicas) las diferencias entre géneros no son tan homogéneas, las mujeres obtienen mayores puntuaciones en unas estrategias y los hombres en otras.

Lo mismo al analizar el efecto del género combinado con el curso. Los datos de esta investigación parecen indicar que los cambios con el tiempo son distintos en las mujeres que en los hombres. Así, el patrón masculino se reproduce más o menos acusado, pero siempre en el mismo sentido. Puntuaciones intermedias o elevadas de las estrategias en primero, una drástica disminución del uso en segundo y una recuperación durante el tercer curso, aunque en cuarto algunas estrategias tienden a aumentar y otras a disminuir, aunque nunca hasta los niveles de primero. No hay patrones tan claros para la evolución de las estrategias en las mujeres y así, mientras unas estrategias tienen una tendencia constantemente creciente (preparación de exámenes), otras se incrementan en segundo y luego disminuyen levemente en tercero para seguir aumentando en cuarto (conceptualización y participación).

Los resultados obtenidos apoyan las ideas de Martín y Camarero (2001) y Cano (2000) sobre la necesidad de realizar análisis multivariados para describir la influencia de las variables, ya que los análisis simples tienden a enmascarar las diferencias y perfiles que posteriormente servirán a los docentes para impulsar eficazmente el desarrollo de las diferentes capacidades de todos sus alumnos.

La aplicación de estos conocimientos permitirá al docente ayudar al estudiante a convertirse en un aprendiz autónomo y responsable de su propio aprendizaje y facilitará la transformación de la enseñanza universitaria actual, basada en el profesor y la transmisión de contenidos, en una formación centrada en el estudiante. En este sentido, la actuación sobre las estrategias de aprendizaje basada en la realidad de cada aula universitaria dotará de mejores y más eficaces herramientas para el aprendizaje de los alumnos, lo que previsiblemente incidirá de forma positiva en la motivación del alumno $\mathrm{y}$, por lo tanto, en su rendimiento.

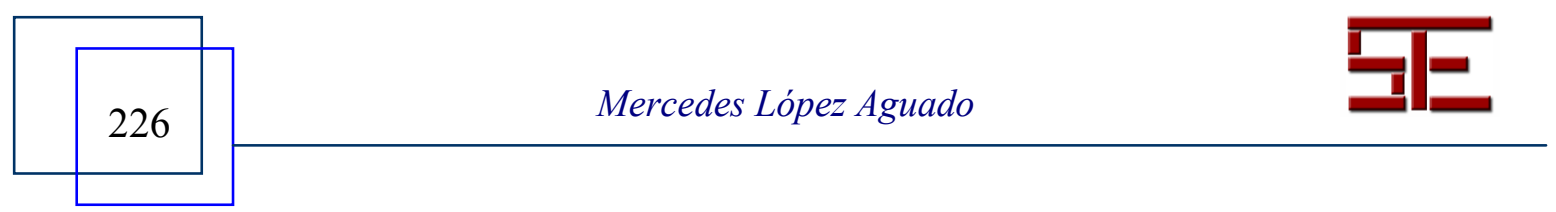




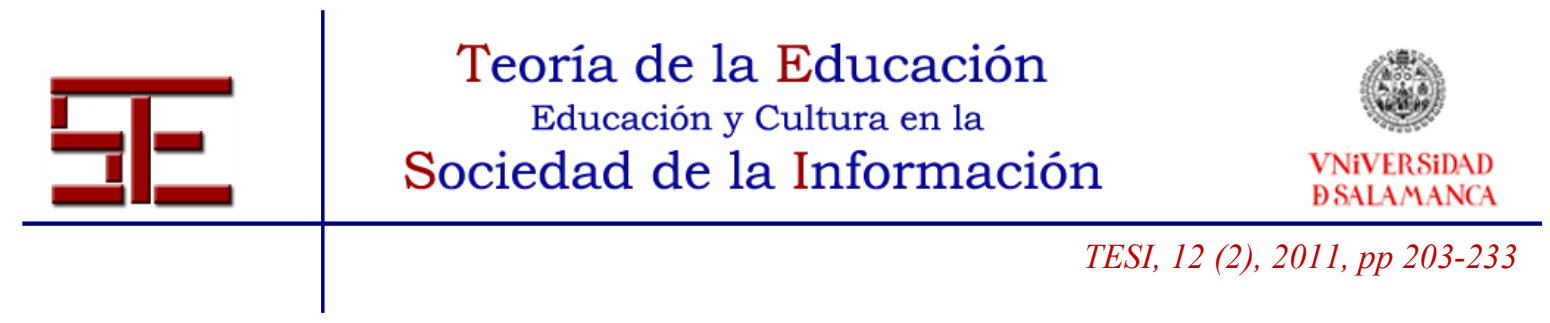

\section{5.- BIBLIOGRAFÍA}

Adeyemi, B. A. (2008). Effects of cooperative learning and problem-solving strategies on junior secondary school students' achievement in social studies. Electronic Journal of Research in Educational Psychology, 6 (3), 691-708. Extraído de http://www.investigacion-psicopedagogica.org/revista/new/english/index.php

Algera, H.F. (2006). Students' achievement goal orientations and their use of selfregulated learning strategies: A cross-cultural (Canada/Russia) comparison. Dissertation Abstracts International Section A: Humanities and Social Sciences, 66 (7-A), 2489.

Beisser, S. R. (2006). An examination of gender differences in elementary constructionist classrooms using Lego/Logo instruction. Computers in the Schools, 22 (3), 7-19.

Bembenutty, H. (2007). Self-regulation of learning and academic delay of gratification: Gender and ethnic differences among college students. Journal of Advanced Academics, 18 (4), 586-616.

Cabanach, R., Valle, A., Gerpe, M., Rodríguez, S., Piñeiro, I. y Rosário, P. (2009). Diseño y validación de un cuestionario de gestión motivacional. Revista de Psicodidáctica, 14 (1), 29-47.

Campbell, M. M. (2007). Motivational systems theory and the academic performance of college students. Journal of College Teaching \& Learning, 4 (7), 11-24.

Cano, F. (2000). Diferencias de género en estrategias y estilos de aprendizaje. Psicothema, 12 (3), 360-367.

Carbonero, M. A., Román, J.M., Martín, L.J. y Reoyo, N. (2009). Efecto del programa de habilidades docentes motivadoras en el profesorado de secundaria. Revista de Psicodidáctica, 14 (2), 229-244.

Choi, J., McKillop, E., Ward, M., \& L'Hirondelle, N. (2006). Sex-specific relationships between route-learning strategies and abilities in a large-scale environment. Environment and Behavior, 38(6), 791-801.

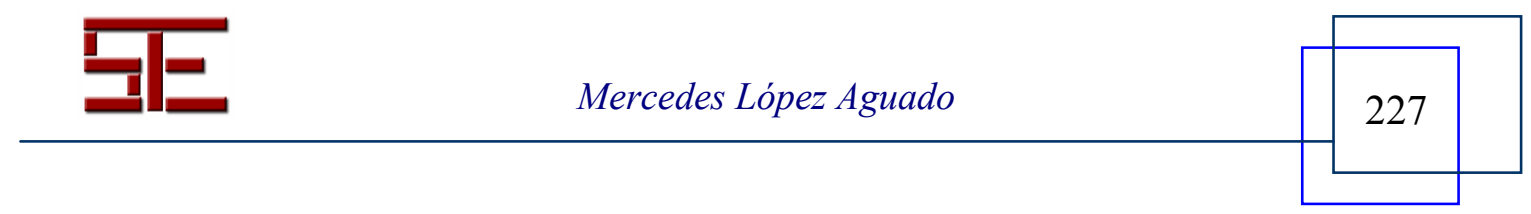




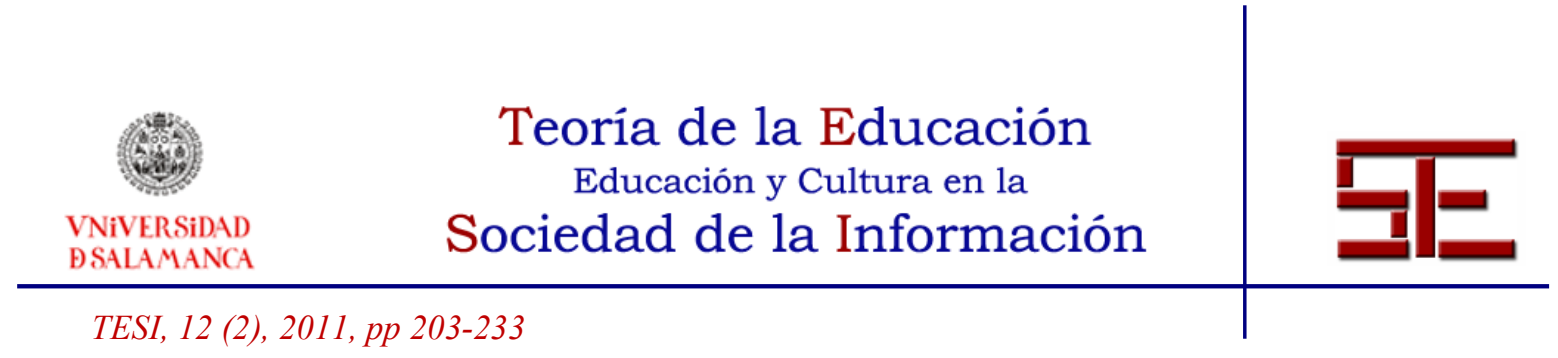

Clarke, R. B. (2007). Undergraduate mathematic students: How do differences in motivation and learning strategy use affect performance? (ProQuest Information \& Learning). Dissertation Abstracts International Section A: Humanities and Social Sciences, 67.

Clayton, K., Blumberg, F. \& Auld, D. P. (2009). The relationship between motivation, learning strategies and choice of environment whether traditional or including an online component. British Journal of Educational Technology, 41(3), 349-364.

Cooper, J. W. (2009). Relationships among behavior-personality variables, preferred learning strategies, and learner characteristics in the workplace. Dissertation Abstracts International Section A: Humanities and Social Sciences, 69 (12-A), 4596.

Correa, M. E., Castro, F. \& Lira, H. (2004). Estudio descriptivo de las estrategias cognitivas y metacognitivas de los alumnos y alumnas de primer año de pedagogía en enseñanza media de la Universidad del Bío-Bío. Teoría, 13, 103110.

De la Fuente, J. y Justicia, F. (2003). Escala de estrategias de aprendizaje ACRAAbreviada para alumnos universitarios. REIPP, Revista Electrónica de Investigación Psicoeducativa y Psicopedagógica, 1 (2), 140-158.

Downing, K., Chan, S., Downing, W., Kwong, T. \& Lam, T. (2008). Measuring gender differences in cognitive functioning. Multicultural Education \& Technology Journal, 2 (1), 4-18.

Entwistle, N. \& Tait, H. (1995). Approaches to studying and perceptions of the learning environment across disciplines. New Directions for Teaching and Learning, (64), 93-103.

Fernández Borrás, J. (coord.) (2006). Evaluación de las preferencias de estudio y las estrategias de aprendizaje de los estudiantes universitarios. Barcelona: Universidad de Barcelona.

Fonseca, M.L. \& Rolo, M.E. (2005). Concepçóes, abordagens e estratégias de aprendizagem no ensino superior. Ciencia Psicológica, 10, 234-247.

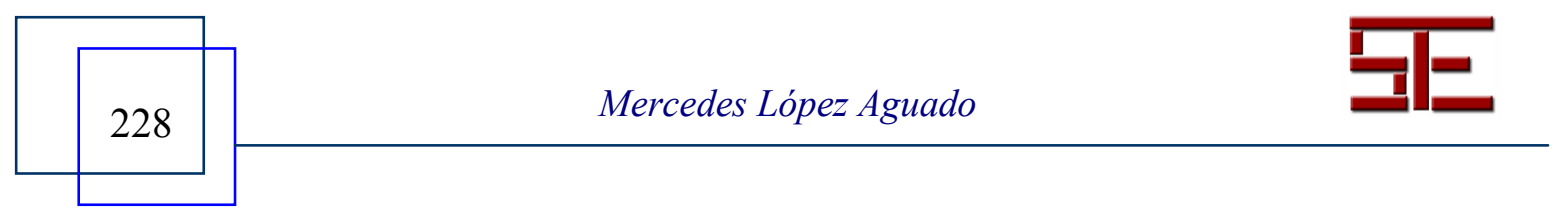




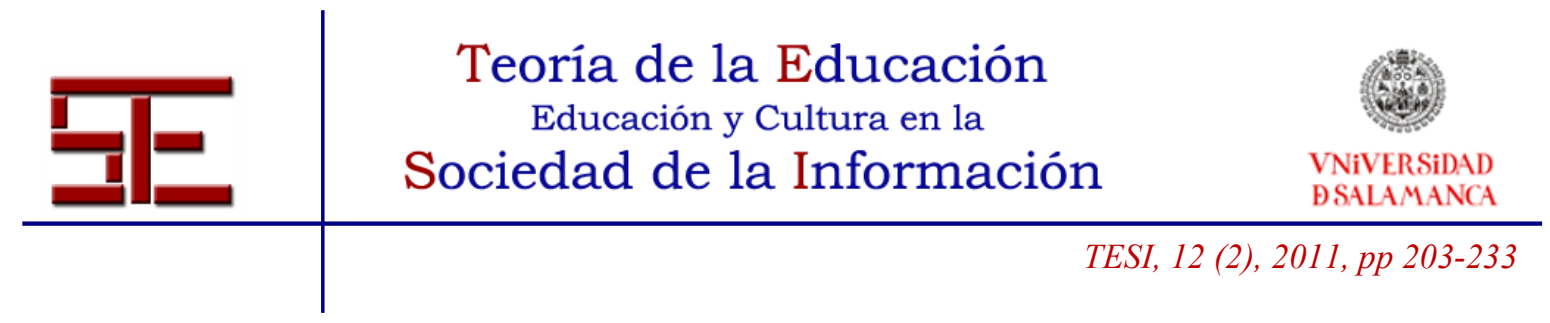

García, M., De la Fuente, J. y Justicia, F. (2002). La autorregulación del aprendizaje en el aula. Proyecto de investigación. Sevilla: Consejería de Educación. Junta de Andalucía.

García, L. A., Hernández, P. \& Luján, I. (1998). Estrategias cognitivas y motivacionales en el aprendizaje de estudiantes universitarios. Evaluación e Intervención psicoeducativa: Revista interuniversitaria de Psicología de la Educación, 1, 1533.

Gargallo, B. (2006). Estrategias de aprendizaje, rendimiento y otras variables relevantes en estudiantes universitarios. Revista de Psicología General y Aplicada, 59 (1-2), 109-130.

Gázquez, J., Pérez, M. C., Ruiz, M. I., Miras, F. \& Vicente, F. (2006). Estrategias de aprendizaje en estudiantes de enseñanza secundaria obligatoria y su relación con la autoestima. International Journal of Psychology and Psychological Therapy, 6 (1), 51-62.

Gil, P., Bernaras, E., Elizalde, L. M. \& Arrieta, M. (2009). Estrategias de aprendizaje y patrones de motivación del alumnado de cuatro titulaciones del Campus de Guipúzcoa. Infancia y aprendizaje, 32 (3), 329-341.

Hernández Pina, F., Rosário, P., Cuesta, J. D., Martínez, P. y Ruiz, E. (2006). Promoción del aprendizaje estratégico y competencias de aprendizaje en estudiantes de primero de universidad: evaluación de una intervención. Revista de Investigación Educativa, 24 (2), 615-631.

Hickendorff, M., Van Putten, C. M., Verhelst, N. D. \& Heiser, W. J. (2010). Individual differences in strategy use on division problems: Mental versus written computation. Journal of Educational Psychology, 102 (2), 438-452.

Ho, I.T. \& Hau, K.T. (2008). Academic achievement in the Chinese context: The role of goals, strategies, and effort. International Journal of Psychology, 43(5), 892-897.

Hong, E., Peng, Y. \& Rowell, L. L. (2009). Homework self-regulation: Grade, gender, and achievement-level differences. Learning and Individual Differences, 19 (2), 269-276.

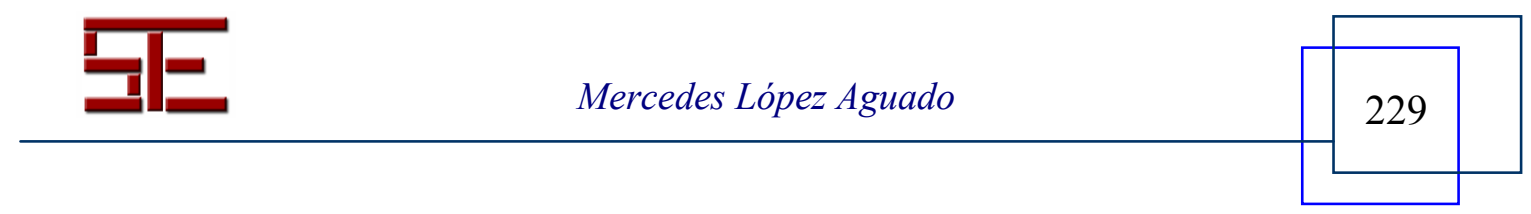




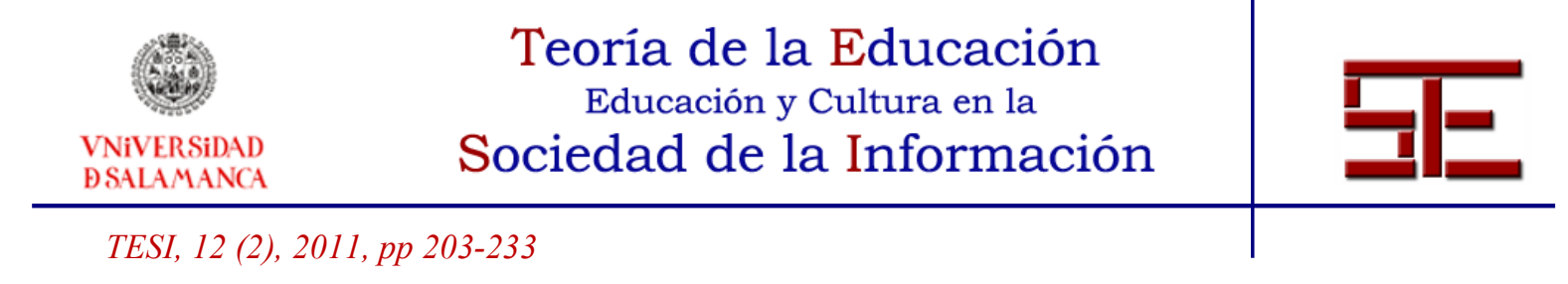

Hong-Nam, K. \& Leavell, A. G. (2006). Language learning strategy use of ESL students in an intensive English learning context. System: An International Journal of Educational Technology and Applied Linguistics, 34 (3), 399-415.

Kay, R. (2007). A formative analysis of how preservice teachers learn to use technology. Journal of Computer Assisted Learning, 23 (5), 366-383.

Khalil, A. (2005). Assessment of language learning strategies used by Palestinian EFL learners. Foreign Language Annals, 38 (1), 108-119.

Kolawole, E. B. (2008). Effects of competitive and cooperative learning strategies on academic performance of Nigerian students in mathematics. Educational Research and Reviews, 3(1), 33-37.

Lai, C. \& Kuo, M. (2007). Gender difference in CALL programs for English as a second language acquisition. Extraído de

http://search.ebscohost.com/login.aspx?direct=true\&db=eric\&AN=ED496190\&lang=es $\&$ site $=$ ehost-live.

Leutwyler, B. (2009). Metacognitive learning strategies: Differential development patterns in high school. Metacognition and Learning, 4 (2), 111-123.

Levine, L. E., Fallahi, C. R., Nicoll-Senft, J., Tessier, J. T., Watson, C. L. \& Wood, R. M. (2008). Creating significant learning experiences across disciplines. College Teaching, 56 (4), 247-254.

Liu, O. L. (2009). Evaluation of a learning strategies scale for middle school students. Journal of Psychoeducational Assessment, 27 (4), 312-322.

López-Aguado, M. (2010). Diseño y análisis del Cuestionario de Estrategias de Trabajo Autónomo (CETA) para estudiantes universitarios. Revista de Psicodidáctica, 15(1), 77-99.

Lynch, D. J. (2008). Confronting challenges: Motivational beliefs and learning strategies in difficult college courses. College Student Journal, 42 (2), 416-421.

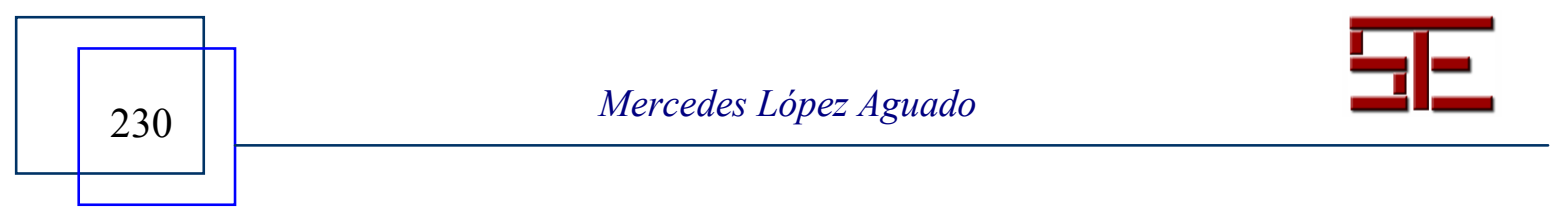




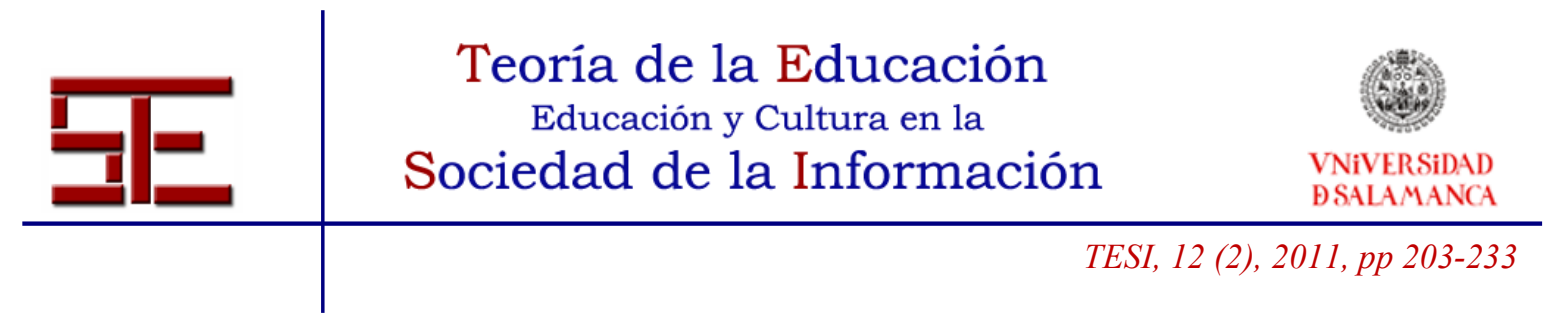

Martín, F. \& Camarero, F. (2001). Diferencias de género en los procesos de aprendizaje en universitarios. Psicothema, 13, 4, 598-604.

Mas, C. \& Medinas, M. (2007). Motivaciones para el estudio en universitarios. Anales de Psicología, 23 (1), 17-24.

Mok, M. M. C., Ma, H. S., Liu, F. Y. F. \& So, E. Y. P. (2005). Multilevel analysis of primary students' perception and deployment of self-learning strategies. Educational Psychology, 25 (1), 129-148.

Monereo, C. (coord.) (2005). Internet y competencias básicas. Aprender a colaborar, a comunicarse, a participar, a aprender. Barcelona: Editorial Graó.

Neumann, R., Parry, S. \& Becher, T. (2002). Teaching and learning in their disciplinary contexts: A conceptual analysis. Studies in Higher Education, 27, 405-417.

Nisbet, D. L., Tindall, E. R. \& Arroyo, A. A. (2005). Language learning strategies and English proficiency of Chinese university students. Foreign Language Annals, 38 (1), 100-107.

Núñez, J. C., González-Pienda, J. A., García, M., González-Pumariega, S., Roces, C., Álvarez, L. y González, M.C. (1998). Estrategias de aprendizaje, autoconcepto y rendimiento académico. Revista Galega de Psicopedagoxía, 7 (10-11), 219-242.

Parpala, A., Lindblom-Ylanne, S., Komulainen, E., Litmanen, T. \& Hirsto, L. (2010). Students' approaches to learning and their experiences of the teaching-learning environment in different disciplines. British Journal of Educational Psychology, 80 (2), 269-282.

Parry, S. (1998). Disciplinary discourse in doctoral theses. Higher Education, 36, 273299.

Pintrich, P. R. \& Zusho, A. (2007). Student motivation and self-regulated learning in the college classroom. En R. Perry \& J. C. Smart (Eds.), The scholarship of teaching and learning in higher education: An evidence-based perspective (pp. 731-810). Dordrecht: Springer.

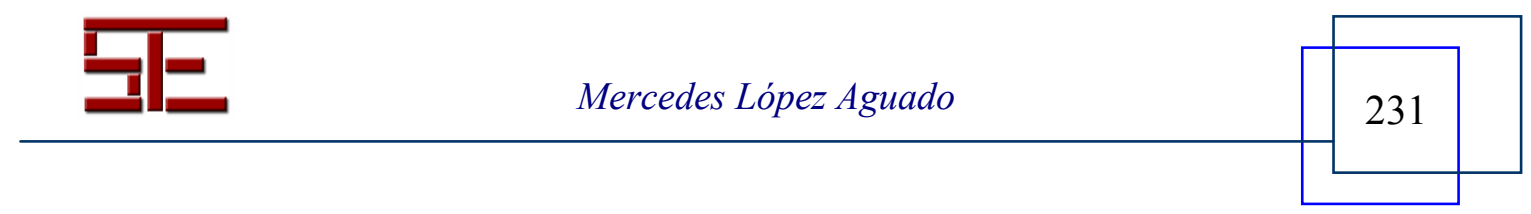




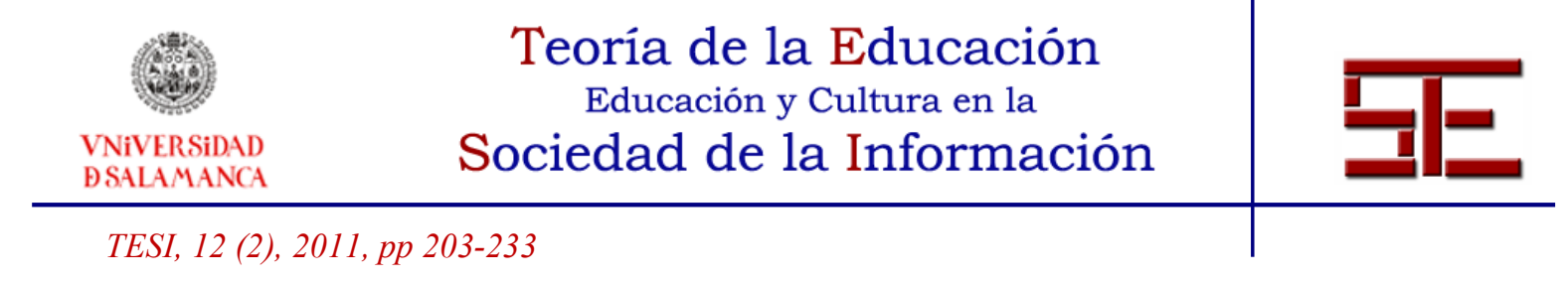

Psaltou-Joycey, A. (2008). Cross-cultural differences in the use of learning strategies by students of Greek as a second language. Journal of Multilingual and Multicultural Development, 29 (4), 310-324.

Rachal, K.Ch., Daigle, S. \& Rachal, W.S. (2007). Learning problems reported by collage students: Are they using learning strategies? Journal of Instructional Psychology, 34 (4), 191-199.

Rinaudo, M.C., de la Barrera, M.L. \& Donolo, D. (2006). Motivación para el aprendizaje en alumnos universitarios. Revista Electrónica de Motivación y Emoción, $\quad$ 22. Consultado el 17/01/2011 en: http://reme.uji.es/reme/numero22/indexsp.html.

Rinaudo, M. C., Chiecher, A. \& Donolo, D. (2003). Motivación y uso de estrategias en estudiantes universitarios. Su evaluación a partir del Motivational Strategies Learning Questionnaire. Anales de Psicología, 19 (1), 107-119.

Rodarte-Luna, B. \& Sherry, A. (2008). Sex differences in the relation between statistics anxiety and Cognitive/Learning strategies. Contemporary Educational Psychology, 33(2), 327-344.

Rodrigues, K. J. (2009). Do learning styles, learning strategies, and student's preference for teacher's teaching philosophy predict student preference for online or in-class courses. Dissertation Abstracts International Section A: Humanities and Social Sciences, 70 (6-A), 1924.

Rosário, P. (2004). Estudar o Estudar: As (Des)venturas do Testas. Porto: Porto Editora.

Schueller, J. M. (2009). Gender and foreign language reading comprehension: The effects of strategy training. En C. Brantmeier (Ed.), Crossing languages and research methods: Analyses of adult foreign language reading (pp. 147-167). Greenwich, CT US: IAP Information Age Publishing.

Smeby, J. (1996). Disciplinary differences in university teaching. Studies in Higher Education, 21, 69-79.

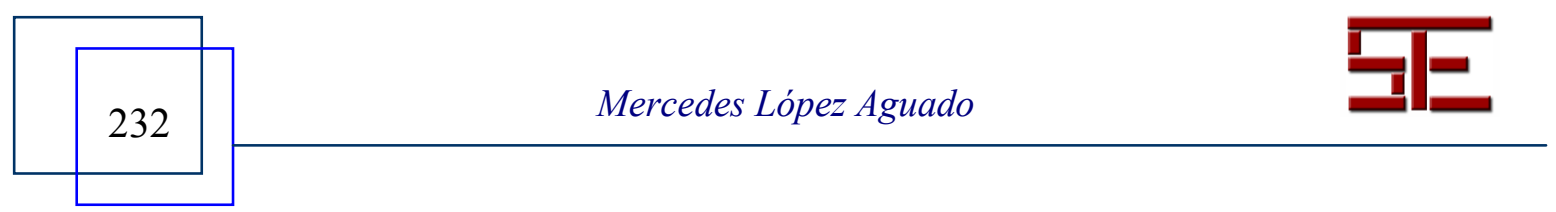




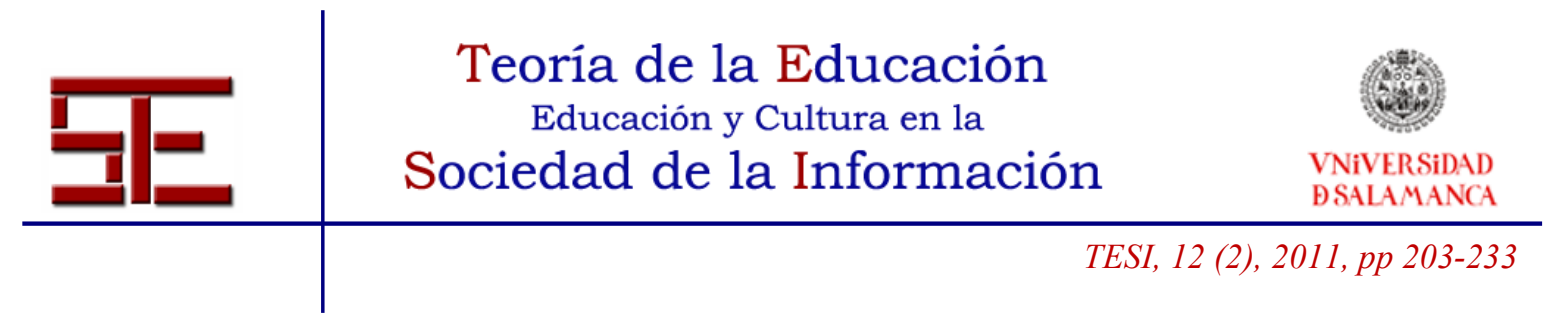

Taasoobshirazi, G. \& Carr, M. (2009). A structural equation model of expertise in college physics. Journal of Educational Psychology, 101(3), 630-643.

Trout, D. K. (2010). Learning strategies preferences, decision-making styles, ways of knowing, and cultural awareness of members of the National Academic Advising Association. Dissertation Abstracts International Section A: Humanities and Social Sciences, 71 (2-A), 425.

Tunur, T., Dohanich, G. P. \& Schrader, L. A. (2010). Pre-exposure to context affects learning strategy selection in mice. Learning \& Memory, 17 (7), 328-331.

Valle, A., González, R., Cuevas, L. M. \& Fernández, A.M. (1998). Las estrategias de aprendizaje: características básicas y su relevancia en el contexto escolar. Revista de Psicodidáctica, 6, 53-68.

Vélez, G. (1999). Aprender a estudiar ¿una cuestión de técnicas? Cuadernos de Educación, Año I, 2, 134-149.

Vega, M. y Beltrán, J.A. (2003). Aprender con tecnología en el aula inteligente. En F. Segovia (Coord.), El aula inteligente: nuevas perspectivas (pp. 101-138). Madrid: Espasa Calpe.

Virtanen, P. \& Nevgi, A. (2010). Disciplinary and gender differences among higher education students in self-regulated learning strategies. Educational Psychology, 30 (3), 323-347.

Webster, B. J., Chan, W.S., Prosser, M.T. \& Watkins, (2009). Undergraduates' learning experience and learning process: Quantitative evidence from the east. Higher Education, 58 (3), 375-386.

Yukselturk, E. \& Bulut, S. (2009). Gender differences in self-regulated online learning environment. Journal of Educational Technology \& Society, 12 (3), 12-22.

Zabalza, M. A. (2002). La enseñanza universitaria. El escenario y sus protagonistas. Madrid: Narcea.

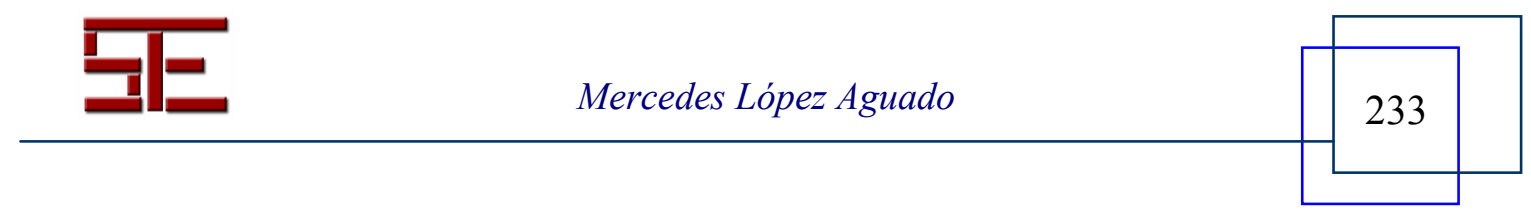


Teoría de la Educación

Educación y Cultura en la

VNiVERSiDAD

DSALAMANCA

Sociedad de la Información

TESI, 12 (2), 2011, pp 203-233

Para citar el presente artículo puede utilizar la siguiente referencia:

López Aguado, M. (2011). Estrategias de aprendizaje en estudiantes universitarios. Diferencias por género, curso y tipo de titulación, en Barrios Vicente, I. M. (Coord.) Mujeres y la sociedad de la Información. Revista Teoría de la Educación: Educación y Cultura en la Sociedad de la Información. Vol. 12, n 2. Universidad de Salamanca, pp. 203-233 [Fecha de consulta: dd/mm/aaaa].

http://campus.usal.es/ revistas_trabajo/index.php/revistatesi/article/view/8279/8283 